\title{
Indirect assessment of hydraulic diffusivity and permeability for unsaturated cement-based material from sorptivity
}

\author{
Chunsheng ZHOU, a,b, Wei CHENc, Wei WANG ${ }^{\mathrm{a}, \mathrm{b}}$, Frédéric Skoczylas ${ }^{\mathrm{c}}$ \\ ${ }^{a}$ Key Lab of Structures Dynamic Behavior and Control (Harbin Institute of Technology), Ministry of Education, \\ Heilongjiang, Harbin 150090, China \\ ${ }^{b}$ School of Civil Engineering, Harbin Institute of Technology, Heilongjiang, Harbin 150090, China \\ ${ }^{c}$ Ecole Centrale de Lille, Laboratoire de Mécanique de Lille, BP 48 F-59650 Villeneuve d'Ascq, France
}

\section{Abstract}

The hydraulic diffusivity, water permeability and relative gas permeability for cement-based materials are indirectly evaluated from measured sorptivity and water vapor sorption isotherms (WVSIs). The dependence of sorptivity on initial saturation degree is first established to help calculate hydraulic diffusivity and other transport properties. An experimental program with a self-scaled preconditioning strategy is also carefully designed and conducted on three concretes to measure their sorptivity, WVSIs as well as permeability to various fluids. It's found that hydraulic diffusivity of ambiguous physical significance may be not a good durability indicator. The predicted water permeability is larger than measured value but at the same order of magnitude. This overestimation is attributed to the required drying preconditioning. The predicted relative water permeability agrees well with reported data. However, the predicted relative gas permeability agrees with the measured data from classical CEMBUREAU method better than that from tri-axial permeameter with higher inlet gas pressure.

Keywords: Concrete (E), Saturation degree (C), Sorptivity (C), Hydraulic diffusivity (C), Permeability (C)

\section{Introduction}

The transport properties of water, the main controller of degradation under various actions including cyclic freezing-thawing, carbonation, steel reinforcement corrosion etc., are significantly important in the quantitative analysis on the deterioration of cement-based materials [1-3]. Under real service, most cement-based materials are rarely saturated in engineering practice. In most

${ }^{*}$ Corresponding author, Tel./Fax: +86 45186289577

Email address: zhouchunsheng.HIT@gmail . com (Chunsheng ZHOU) 
cases, the water transport in unsaturated porous material is usually described by Darcy's law in terms of either hydraulic diffusivity or permeability $[4,5]$, which strongly depend on the water saturation degree with very high non-linearity [6]. The models for these two significant properties are fundamentally central in the quantitative analysis of durability and service life for cementbased materials under various aggressive environments [1].

The direct measurements of hydraulic diffusivity and permeability for modern cement-based materials with low water to cement ratio, which are much denser and stiffer than porous soils, will face great practical problems [7, 8]. The direct testing of hydraulic diffusivity usually employs the non-destructive detecting of instant water content profile in one-dimension capillary suction process, which requires special equipment like Gamma Ray Attenuation, Neutron Radiography and Nuclear Magnetic Resonance (NMR) [3,9] etc. Several methods indirectly deriving the hydraulic diffusivity from sorptivity, another transport property very easy to measure, have also been proposed $[10,11]$. Based on the assumed model of specific law for hydraulic diffusivity function, the hydraulic diffusivity can be obtained with certain empirical parameters, which are dependent on the pore structure of concerned materials [11]. In another aspect, although several advanced experimental techniques or facilities have been developed [12-14], the direct measurement of saturated water permeability for dense cement-based material is still a big problem, not mentioning the unsaturated situation [3]. Indirectly, another conceptual model has been proposed to derive unsaturated water permeability from only pore size distribution but limited to rocks in petroleum industry [15]. In addition, another implicit model giving relative permeability to water and gas from only water retention curve have been also initially deduced for soil materials [16, 17]. It is further extended to cement-based materials $[8,18]$ and calibrated mainly by gas permeability $[19,20]$, which is much easier to measure over water permeability. However, the fundamental parameters like tortuosity factor in the critical models for water retention curve and relative permeability, which are originally developed for soils [21, 22], vary in a great range and are rather hard to accurately determine for cement-based material with pore structure obviously different from soil materials [16, 19, 23, 24]. Moreover, the hydraulic diffusivity and water permeability, different transport properties deducing from the unique Darcy's law for water migration, may be not consistent and contradict with each other on some specific characteristics [25]. It makes the indirect methods unconvincing and even questionable in evaluating unsaturated permeability from only water retention characteristics for cement-based materials.

Recently, several unified models for hydraulic diffusivity, unsaturated water permeability as well as relative gas permeability are well established and verified [25-27]. Provided that hydraulic diffusivity observes exponential law with the shape parameter representing relative tortuosity of 
overall transport path for unsaturated porous material, the hydraulic diffusivity can be determined from sorptivity measurement [26]. Furthermore, after determination of water retention curve for specific cement-based material, the water permeability and relative gas permeability can be explicitly and neatly calculated [25]. The model for permeability can be further extended for relative ion diffusivity with clear physical meaning [27]. As a result, all these important mass transport properties can be consistently characterized with only two measurable fundamental quantities, the water retention curve and shape parameter. For cement-based materials, the water retention characteristics is usually measured by the water vapour sorption experiments, which is rather time-consuming but relatively straightforward [18, 28-30]. Then, how to conveniently determine the shape parameter is attractive but still need further investigation. On another hand, it should be noted that these unified models are established and individually validated by pieces of experimental data grasped from the literature $[25,27]$, which are measured on different cementitious materials by different authors. Importantly, the newly proposed models for saturated water permeability and relative water permeability have not been validated yet by experimental data in previous studies. Further research work is still needed to put forward the comprehensive verification of these unified models.

Based on the established consistent models for various transport properties, an indirect method assessing hydraulic diffusivity and permeability from sorptivity is proposed and verified for unsaturated cement-based materials. The theoretical relationships between sorptivity for initially unsaturated cement-based material and other transport properties are firstly analyzed in Section 2. In Section 3, a thorough experimental program is introduced to measure water vapour sorption isotherms (WVSIs), capillary sorptivity and permeability for concrete materials with various saturation degrees. Based on the measured WVSIs and capillary sorptivity, the unsaturated permeability to water and gas are further calculated and verified with experimental results in Section 4. Finally, some concluding remarks are given in Section 5.

\section{Theoretical background}

\subsection{Relationship between sorptivity and hydraulic diffusivity}

Sorptivity $S\left(\mathrm{~L} \cdot \mathrm{T}^{-0.5}\right)$, which is strongly dependent on initial water saturation degree, is an important durability indicator easily to measure from one-dimensional water suction test [5]. To facilitate the following analysis on sorptivity, hydraulic diffusivity as well as permeability for partially saturated cement-based materials, the water saturation degree $\omega(-)$ and initial water saturation degree $\omega_{\mathrm{i}}(-)$ are first defined as,

$$
\omega=\theta / \theta_{\mathrm{s}}, \omega_{\mathrm{i}}=\theta_{\mathrm{i}} / \theta_{\mathrm{s}}
$$


in which $\theta(-)$ is the volumetric water content. Subscript " $i$ ", "s" denotes initial unsaturated state and fully saturated state, respectively. For an isotropic porous material with initial water saturation degree $\omega_{\mathrm{i}}$, the cumulative volume of water suction per unit area of the inflow surface $V_{\mathrm{w}}(\mathrm{L})$ will linearly increase with the square root of the suction time span $t(\mathrm{~T})$,

$$
V_{\mathrm{w}}=S\left(\omega_{\mathrm{i}}\right) \sqrt{t}
$$

from which the sorptivity $S\left(\omega_{\mathrm{i}}\right)$ for initially unsaturated cement-based materials can be easily regressed. Actually, sorptivity $S\left(\omega_{\mathrm{i}}\right)$ is usually obtained by fitting the measured $V_{\mathrm{w}}$ at different time $t$ to the below relationship $[5,31]$

$$
V_{\mathrm{w}}=S\left(\omega_{\mathrm{i}}\right) \sqrt{t}+B
$$

in which $B(\mathrm{~L})$ is a correct term accounting for the filling of open porosity on the inflow surface (surface effect). This measurement can be conducted in general laboratory.

In essence, the water suction process in unsaturated concrete material can be also described by unsaturated flow theory, which employs the extended Darcy's law to quantify the water transport in terms of hydraulic diffusivity $D(\omega)\left(\mathrm{L}^{2} / \mathrm{T}\right)[4,5]$. In another words, the water transport can be quantified by either sorptivity $S\left(\omega_{\mathrm{i}}\right)$ or hydraulic diffusivity $D(\omega)$, which determines the implied intimate relationship between them. In another paper published by the corresponding author, the relationship between sorptivity $S$ and hydraulic diffusivity $D(\omega)$ have been strictly derived, provided that the hydraulic diffusivity $D(\omega)$ obeys exponential law [26]. For cement-based materials, the hydraulic diffusivity usually observes exponential law [5,32], which is also recommended over power law from the viewpoint of relative permeability to water and gas [11,27],

$$
D(\omega)=D_{0} \exp \left(n_{0} \omega\right)
$$

in which $D_{0}\left(\mathrm{~L}^{2} / \mathrm{T}\right), n_{0}(-)$ is named as initial hydraulic diffusivity and shape parameter in accordance with saturation degree $\omega=0$, respectively. After measuring sorptivity $S$ for totally dried material, the initial hydraulic diffusivity $D_{0}$ thus $D(\omega)$ can be determined by either General Solving Approach (GSA) [26] or another approximate method [33] with known shape parameter $n_{0}$. More generally, for an unsaturated porous material with initial water saturation degree $\omega_{\mathrm{i}}$, if the hydraulic diffusivity observes exponential law in terms of reduced water saturation degree $\Theta(-)$ with shape parameter $n_{\mathrm{i}}(-)$,

$$
\Theta=\frac{\theta-\theta_{\mathrm{i}}}{\theta_{\mathrm{s}}-\theta_{\mathrm{i}}}, \quad D(\Theta)=D_{\mathrm{i}} \exp \left(n_{\mathrm{i}} \Theta\right)
$$


where $D_{\mathrm{i}}$ and $n_{\mathrm{i}}$ denotes the hydraulic diffusivity and shape parameter corresponding to $\theta=\theta_{\mathrm{i}}$ $(\Theta=0)$. From the General Solving Approach (GEA) proposed by the corresponding author [26], the relationship between hydraulic diffusivity $D_{\mathrm{i}}$ and sorptivity $S\left(\omega_{\mathrm{i}}\right)$ may write

$$
D_{\mathrm{i}}=\tau\left(n_{\mathrm{i}}\right)\left[\frac{S\left(\omega_{\mathrm{i}}\right)}{\theta_{\mathrm{s}}\left(1-\omega_{\mathrm{i}}\right)}\right]^{2}
$$

in which $\tau(-)$ is a coefficient determined only by the shape parameter $n_{\mathrm{i}}$. For more detailed information, one can refer to reference [26]. Theoretically, the calculation of coefficient $\tau$ from GEA is very complicated and time-consuming, provided that the shape parameter $n_{\mathrm{i}}$ is known. Approximately, the relationship between coefficient $\tau$ and shape parameter $n_{\mathrm{i}}$, which is tabulated in reference [26], can be well approximated by the following function Equation (7) with very high correlation coefficient $R^{2}=0.9999$, as shown in Figure 1 .

$$
\tau\left(n_{\mathrm{i}}\right)=\exp \left(-0.1153-0.7341 n_{\mathrm{i}}-0.0069 n_{\mathrm{i}}^{2}\right)
$$

Another approximate calculation of $\tau$ from shape parameter $n_{\mathrm{i}}$, suggested by Parlange and his co-authors [11,33], yields

$$
\tau\left(n_{\mathrm{i}}\right)=\frac{1}{\left(2 n_{\mathrm{i}}^{-1}-n_{\mathrm{i}}^{-2}\right) \exp \left(n_{\mathrm{i}}\right)-n_{\mathrm{i}}^{-1}+n_{\mathrm{i}}^{-2}}
$$

In Figure 1, the approximate relationship between coefficient $\tau$ and shape parameter $n_{\mathrm{i}}$ in Equation (8) above is also presented. From Figure 1, one can see that the fitting function (7) can well approximate the coefficient $\tau$ strictly calculated through GEA. When shape parameter $n_{\mathrm{i}}$ is relatively big, the solution of $\tau$ from Parlange model agrees with the GEA well. However, the gap between them gets broaden as shape parameter $n_{\mathrm{i}}$ becomes smaller.

Significantly, shape parameter $n_{0}$ determines not only the shape of hydraulic diffusivity with respect to water saturation degree $\omega$ (see Equation (4)), but also the water content profile during one-dimensional capillary suction test [26]. Moreover, the exponential law with shape parameter $n_{0}$ can be also employed to quantified the relative tortuosity of overall mass transport path for unsaturated concrete material, which determines the relative fluid permeability and ion diffusivity [27]. As an extraordinary important parameter in quantifying mass transport properties including sorptivity, hydraulic diffusivity and relative permeability, shape parameter $n_{0}$ can be determined by fitting the hydraulic diffusivity $D(\omega)$ to the exponential law, which can be experimentally measured from water penetration profiles [34, 35]. The problem for this method lies in the difficulty of measuring the instant water profile non-destructively, which usually requires some special techniques, such as Gamma Ray Attenuation, Nuclear Magnetic Resonance (NMR) [3] and 


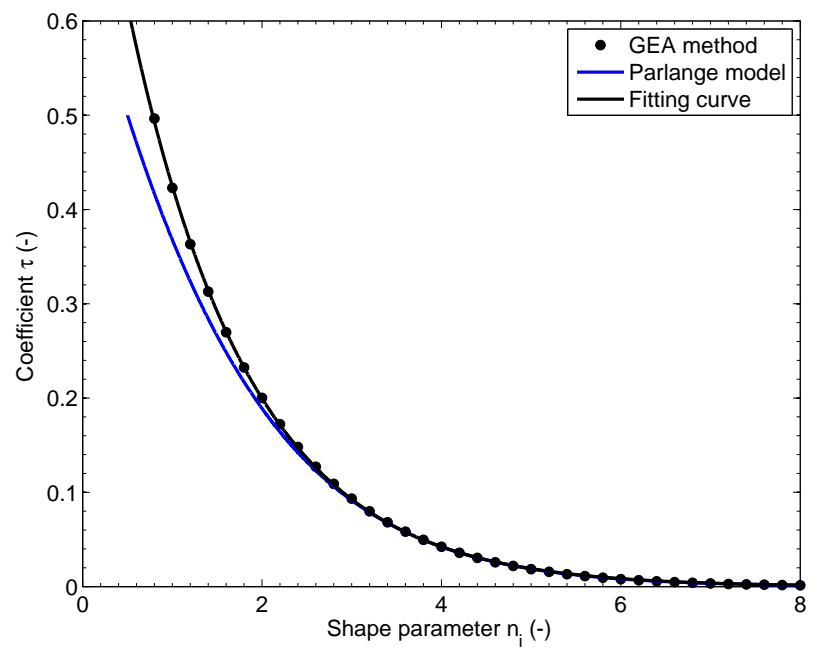

Figure 1: The relationship between coefficient $\tau\left(n_{\mathrm{i}}\right)$ and shape parameter $n_{\mathrm{i}}$.

Neutron Radiography [9] etc. These experiments cannot be generally afforded, thus other easy methods are needed to assess shape parameter $n_{0}$. Herein a simple method is proposed to obtain shape parameter $n_{0}$ from sorptivity measurement for initially unsaturated cement-based materials, which can be generally carried out.

\subsection{Assessment of shape parameter and initial hydraulic diffusivity}

The hydraulic diffusivity $D(\omega)$ and capillary sorptivity $S$ are strongly affected by water saturation degree [36]. After introducing reduced water saturation degree $\Theta$ in Equation (5), the saturation degree $\omega$ can be expressed as,

$$
\omega=\omega_{\mathrm{i}}+\left(1-\omega_{\mathrm{i}}\right) \Theta
$$

Therefore, for an cement-based material with initial water saturation degree $\omega_{\mathrm{i}}$, the exponential hydraulic diffusivity can be calculated as,

$$
D(\omega)=D\left(\Theta, \omega_{\mathrm{i}}\right)=D_{0} \exp \left[n_{0}\left(\omega_{\mathrm{i}}+\left(1-\omega_{\mathrm{i}}\right) \Theta\right)\right]
$$

which can be further arranged as

$$
D\left(\Theta, \omega_{\mathrm{i}}\right)=\left[D_{0} \exp \left(n_{0} \omega_{\mathrm{i}}\right)\right] \times \exp \left[n_{0}\left(1-\omega_{\mathrm{i}}\right) \Theta\right]
$$

Comparing Equations (5) and (11), it is easy to know that, for the unsaturated case with initial water saturation $\omega_{i}$, the hydraulic diffusivity also observes exponential law with respect to reduced water saturation $\Theta$ and

$$
D_{\mathrm{i}}=D_{0} \exp \left(n_{0} \omega_{\mathrm{i}}\right), n_{\mathrm{i}}=n_{0}\left(1-\omega_{\mathrm{i}}\right)
$$


The GEA can be also applied to this situation and gives the relationship between $D_{\mathrm{i}}$ and $n_{\mathrm{i}}$ in the same way, as shown in Equation (6). From Equations (6) and (12), the relationship between shape parameter $n_{0}$ and sorptivity $S\left(\omega_{\mathrm{i}}\right)$ for cement-based material with initial saturation degree $\omega_{\mathrm{i}}$ is,

$$
\left[\frac{S\left(\omega_{\mathrm{i}}\right)}{\theta_{\mathrm{s}}\left(1-\omega_{\mathrm{i}}\right)}\right]^{2}-\frac{D_{0} \exp \left(n_{0} \omega_{\mathrm{i}}\right)}{\tau\left[n_{0}\left(1-\omega_{\mathrm{i}}\right)\right]}=0
$$

which can be further re-arranged as,

$$
\frac{S\left(\omega_{\mathrm{i}}\right)}{\theta_{\mathrm{s}}}=\sqrt{\frac{D_{0} \exp \left(n_{0} \omega_{\mathrm{i}}\right)}{\tau\left[n_{0}\left(1-\omega_{\mathrm{i}}\right)\right]}}\left(1-\omega_{\mathrm{i}}\right)
$$

Then, the relative sorptivity $S_{\mathrm{r}}(-)$ can be given as,

$$
S_{\mathrm{r}}\left(\omega_{\mathrm{i}}\right)=\frac{S\left(\omega_{\mathrm{i}}\right)}{S\left(\omega_{\mathrm{i}}=0\right)}=\sqrt{\frac{\tau\left(n_{0}\right) \exp \left(n_{0} \omega_{\mathrm{i}}\right)}{\tau\left[n_{0}\left(1-\omega_{\mathrm{i}}\right)\right]}}\left(1-\omega_{\mathrm{i}}\right)
$$

After measuring the sorptivity $S\left(\omega_{\mathrm{i}}\right)$ at different levels of initial saturation degree $\omega_{\mathrm{i}}$, the shape parameter $n_{0}$ and initial hydraulic diffusivity $D_{0}$ can be obtained by fitting the measured sorptivity $S\left(\omega_{\mathrm{i}}\right)$ at various saturation degree $\omega_{\mathrm{i}}$ to the above Equation (14). Then, the hydraulic diffusivity $D(\omega)$ is indirectly assessed for cement-based materials.

\subsection{Determination of relative permeability to water and gas}

From the unified models for various mass transport properties, the relative permeability to water and gas can be theoretically calculated from hydraulic diffusivity together with water retention curve model $[25,27]$. The water retention curve model characterizes the relationship between water saturation degree $\omega$ and corresponding capillary pressure head $h_{\mathrm{c}}(\mathrm{L})$, which is proposed to be quantified by the Zhou model as [25],

$$
\omega=\left[1-\alpha+\alpha \exp \left(\beta h_{\mathrm{c}}\right)\right]^{-1}
$$

where $\alpha(-)$ and $\beta\left(\mathrm{L}^{-1}\right)$ are two fitting parameters. Then, the capacity function $C(\omega)\left(\mathrm{L}^{-1}\right)$ can be explicitly calculated as,

$$
C(\omega)=\frac{\theta_{\mathrm{s}} \mathrm{d} \omega}{\mathrm{d} h_{\mathrm{c}}}=\beta \theta_{\mathrm{s}} \omega[1+(\alpha-1) \omega]
$$

Furthermore, the water permeability $k_{\mathrm{w}}\left(\mathrm{L}^{2}\right)$ can be evaluated from hydraulic diffusivity and capacity function as $[5,25]$,

$$
k_{\mathrm{w}}(\omega)=\frac{\mu_{\mathrm{w}}}{\rho_{\mathrm{w}} g} D(\omega) C(\omega)
$$


where $\mu_{\mathrm{w}}\left(\mathrm{M} \cdot \mathrm{L}^{-1} \cdot \mathrm{T}^{-1}\right), \rho_{\mathrm{w}}$ and $g$ is the dynamic viscosity, density of liquid water and gravitational acceleration, respectively. Therefore, the saturated water permeability $k_{\mathrm{sw}}\left(\mathrm{L}^{2}\right)$ and relative water permeability $k_{\mathrm{rw}}(-)$ can be yielded as [25]

$$
k_{\mathrm{sw}}=\mu_{\mathrm{w}} \alpha \beta \theta_{\mathrm{s}} D_{0} \exp \left(n_{0}\right) / \rho_{\mathrm{w}} g
$$

and

$$
k_{\mathrm{rw}}(\omega)=\exp \left[n_{0}(\omega-1)\right]\left[\omega+(\alpha-1) \omega^{2}\right] / \alpha
$$

If the relationship between relative water permeability $k_{\mathrm{rw}}$ and relative gas permeability $k_{\mathrm{rg}}(-)$ is quantified by the Burdine model $[15,25]$, then the relative gas permeability can be formulated from relative water permeability $k_{\mathrm{rw}}(\omega)$ as,

$$
k_{\mathrm{rg}}(\omega)=\exp \left(-n_{0} \omega\right)\left[1-\frac{\omega+(\alpha-1) \omega^{2}}{\alpha}\right]
$$

After evaluating shape parameter $n_{0}$ and fitting parameter $\alpha$, the relative permeability to water and gas $k_{\mathrm{rw}, \mathrm{rg}}$ can be determined through Equations (20) and (21). It is worth noting that, although parameter $\alpha$ may vary in several orders of magnitude hence significantly affects water permeability $k_{\mathrm{sw}}$, it has rather limited effect on relative permeability to water and gas $k_{\mathrm{rw}}$, rg due to the dominant role of shape parameter [25, 27].

\section{Experimental program and procedures}

In above Section 2, the hydraulic diffusivity of exponential law is theoretically derived from sorptivity measured on porous materials with various initial saturation degrees. Together with water retention model, the water permeability and relative gas permeability can be further explicitly formulated. To verify these unified models describing sorptivity, hydraulic diffusivity, water permeability as well as relative gas permeability in a consistent way, a thorough experimental program is further designed and carried out.

\subsection{Materials and specimens}

As possible candidates for long-term nuclear repository, three concrete materials are designed and prepared. Their mix proportioning are detailed in Table 1. Since the important differences between these three concrete materials are the water content and thus workability, they are abbreviated as C19, C29 and C39 for concrete materials with water to cement ratio of 0.19, 0.29 and 0.39 , respectively. After mixing, large-scale concrete beams are casted and 24 hours later cured in lime-saturated water of constant temperature $20^{\circ} \mathrm{C}$ for 6 months before further processing. At 
Table 1: Mix proportioning of three concrete materials

\begin{tabular}{lccl}
\hline Proportioning/Property & C19 & C29 & C39 \\
\hline Sand (Limestone, $\left.0-5 \mathrm{~mm}, \mathrm{~kg} / \mathrm{m}^{3}\right)$ & & 729 & \\
Gravel (Limestone, $\left.5-12 \mathrm{~mm}, \mathrm{~kg} / \mathrm{m}^{3}\right)$ & & 864 & \\
Cement (CEM V/A, $42.5 \mathrm{~N}, \mathrm{~kg} / \mathrm{m}^{3}$ ) & & 393 & \\
Superplasticizer (Glenium $\left.27, \mathrm{~kg} / \mathrm{m}^{3}\right)$ & & 10.0 & \\
Water $\left(\mathrm{kg} / \mathrm{m}^{3}\right)$ & 75.2 & 114.0 & 153.8 \\
\hline Water to cement ratio (-) & 0.19 & 0.29 & 0.39 \\
Capillary porosity (\%) & 7.26 & 8.96 & 11.70 \\
Cylinder strength (MPa) & 71 & 67 & 55 \\
Elastic modulus (GPa) & 43.4 & 43.3 & 33.6 \\
\hline
\end{tabular}

the end of the curing period, long cylinders of diameter $65 \mathrm{~mm}$ (about 5 times the maximum size of coarse aggregates, MSA) are randomly cored from well-hydrated concrete beams. Then, some disk specimens of different thickness but identical diameter $65 \mathrm{~mm}$ are all wet sawed from the central part of these cylinders and prepared for various experiments including water vapour sorption experiment, fluids permeability measurement, sorptivity measurement and relative gas permeability measurement. All these experiments are further given out one by one in the following sections.

\subsection{Water vapour sorption experiments}

The water vapour sorption experiments are conducted by means of the traditional saturated salt solution method $[30,37,38]$, which is easy to carry out but rather time-consuming. To save time and obtain representative results of water vapour sorption, sufficiently large disk specimens of small thickness $20 \mathrm{~mm}$ are sawed and used [39]. As all concrete materials with cement CEM V/A are cured in lime-saturated water for 6 months, the disk specimens of size $\phi 65 \mathrm{~mm} \times 20 \mathrm{~mm}$ are thought to be saturated after immersion in water for another 7 days. After recording the saturated mass $m_{\mathrm{s}}$ to $0.01 \mathrm{~g}$ for each specimen, 14 specimens for each concrete material are first subjected to the desorption drying in 7 hermetic chambers with different relative humidity, which are controlled as constant $98 \%, 92 \%, 85 \%, 75 \%, 59 \%, 43 \%$ and $11 \%$ by various saturated salt solution under the atmospheric pressure [37, 40]. Their masses are monitored every 7 days. If the relative mass change is less than $0.1 \%$, moisture equilibrium with controlled ambient $\mathrm{RH}$ is thought to be reached and the equilibrium mass $m_{\mathrm{e}}$ in the desorption cycle is recorded. After that, all specimen are then oven-dried under $60^{\circ} \mathrm{C}$ until mass stabilization. If the relative mass change is less than $0.1 \%$ in 7 days, totally dried state is thought to be reached and the dried mass $m_{\mathrm{d}}$ is recorded. Af- 
Table 2: The equilibrium water content and saturation degree in first cycle desorption and adsorption experiments.

\begin{tabular}{|c|c|c|c|c|c|c|c|c|c|}
\hline Relativ & umidity $R H$ ( & & $11 \%$ & $43 \%$ & $59 \%$ & $75 \%$ & $85 \%$ & $92 \%$ & $98 \%$ \\
\hline \multirow{6}{*}{$\begin{array}{l}\text { Water } \\
\text { content } w \\
(\%)\end{array}$} & \multirow{3}{*}{ Desorption } & C19 & 1.655 & 2.627 & 2.893 & 3.304 & 3.612 & 3.678 & 3.711 \\
\hline & & C29 & 1.769 & 2.680 & 3.265 & 4.175 & 3.939 & 3.980 & 4.469 \\
\hline & & C39 & 1.331 & 2.967 & 3.427 & 4.394 & 4.897 & 5.063 & 5.727 \\
\hline & \multirow{3}{*}{ Adsorption } & C19 & 0.012 & 0.456 & 0.777 & 1.602 & 2.188 & 2.710 & 3.178 \\
\hline & & $\mathrm{C} 29$ & 0.022 & 0.486 & 0.934 & 1.868 & 2.252 & 2.843 & 3.831 \\
\hline & & C39 & 0.046 & 0.565 & 0.872 & 1.739 & 2.484 & 3.287 & 4.771 \\
\hline \multirow{6}{*}{$\begin{array}{l}\text { Saturation } \\
\text { degree } \omega \\
(-)\end{array}$} & \multirow{3}{*}{ Desorption } & C19 & 0.416 & 0.645 & 0.741 & 0.830 & 0.876 & 0.883 & 0.924 \\
\hline & & C29 & 0.374 & 0.605 & 0.720 & 0.862 & 0.884 & 0.908 & 0.946 \\
\hline & & C39 & 0.256 & 0.509 & 0.641 & 0.821 & 0.870 & 0.926 & 0.955 \\
\hline & \multirow{3}{*}{ Adsorption } & C19 & 0.003 & 0.112 & 0.198 & 0.403 & 0.530 & 0.651 & 0.792 \\
\hline & & $\mathrm{C} 29$ & 0.005 & 0.109 & 0.206 & 0.386 & 0.505 & 0.649 & 0.811 \\
\hline & & C39 & 0.009 & 0.097 & 0.163 & 0.325 & 0.441 & 0.601 & 0.795 \\
\hline
\end{tabular}

ter drying to constant mass, the first cycle adsorption is further carried out to obtained equilibrium mass $m_{\mathrm{e}}$ in wetting. Similar to desorption and oven drying, the same criterion for moisture equilibrium is adopted. From the first cycle desorption and adsorption experiments, the water content $w$ and corresponding saturation degree $\omega$ can be calculated from totally dried mass $m_{\mathrm{d}}$, saturated mass $m_{\mathrm{S}}$ and equilibrium mass $m_{\mathrm{e}}$ in desorption and adsorption process as,

$$
w=\left(m_{\mathrm{e}}-m_{\mathrm{d}}\right) / m_{\mathrm{d}}, \quad \omega=\frac{m_{\mathrm{e}}-m_{\mathrm{d}}}{m_{\mathrm{s}}-m_{\mathrm{d}}}
$$

Finally, the water vapour desorption and adsorption isotherms giving the relationship between equilibrated water content and ambient relative humidity are obtained. The first cycle desorption, oven drying and adsorption process took about 22 weeks, 7 weeks and almost 1 year, respectively. The water content $w$ and saturation degree $\omega$ are averaged over two specimens in balance with each relative humidity and listed in Table 2.

The first cycle desorption and adsorption isotherms can be further translated into the water retention curve, which quantify the relationship between capillary pressure head $h_{\mathrm{c}}$ and the saturation degree $\omega$ for cementitious materials. The capillary pressure head $h_{\mathrm{c}}$ can be deduced from the controlled ambient relative humidity $R H$ from the Kelvin equation as [41, 42],

$$
h_{\mathrm{c}}=\frac{P_{\mathrm{c}}}{\rho_{\mathrm{w}} g}=-\frac{R T}{M_{\mathrm{w}} g} \ln R H
$$

in which $R(\mathrm{~J} / \mathrm{mol} / \mathrm{K}), T(\mathrm{~K})$ and $M_{\mathrm{w}}(\mathrm{kg} / \mathrm{mol})$ is the universal gas constant, absolute temperature 
and molar mass of water, respectively. After obtaining saturation degree $\omega$ in balance with different relative humidity, the water retention data can be further calculated, which will facilitate the analysis of water permeability and relative gas permeability for unsaturated concrete materials.

\subsection{Measurement of permeability to liquids and gas}

By a steady state permeameter with well-designed tri-axial pressure cell [14], the permeability to liquid water, argon gas and ethanol for three concrete materials are measured one by one. The detailed information about the permeameter used herein can be found in early publication [14]. To experimentally measure the saturated liquid permeability, 3 disk specimens of size $\phi 65 \mathrm{~mm} \times 30 \mathrm{~mm}$ for each concrete material are wet sawed and immersed in water for another 7 days to attain saturation. Then the water permeability is first measured on these water-saturated specimens. The thickness for these specimens (2.5 times MSA) is relatively small to make the difficult measurement of water permeability possible. To measure the intrinsic gas permeability, all specimens were further oven-dried at $60^{\circ} \mathrm{C}$ to constant mass. Then, the gas permeability testing were carried out on totally dried specimens. Later, the totally dried concrete specimens are re-saturated with ethanol until constant mass by vacuum method. Similar to the water permeability measurement, the ethanol permeability were also performed on these specimens vacuum saturated with ethanol.

Both water and ethanol permeability are measured by steady method from Darcy's law. Each specimen is amounted to the highly developed permeameter and then sealed on circumferential surface by confining pressure $P_{\mathrm{c}}$ of 30 bars. Relative inlet pressure $P_{\mathrm{i}}$ of 15 bars are further continuously applied on the bottom surface by a Gilson type pump while the top circular surface is open to the atmosphere. It can also help to ensure the specimen saturated with the concerned liquids. Under the action of pressure difference, the liquid will flow through the specimen from bottom to top surface. Only one dimensional flow is guaranteed with good sealing effect on circumferential surface from high confining pressure. The injected liquid flow is monitored every 2 hours until the latest 5 continuous injected volumes of liquid observe linear law with high correlation coefficient $R^{2}$ larger than 0.999 . Then, the steady entry flow rate $Q(\mathrm{~mL} / \mathrm{min})$ can be obtained by linear regression and the water or ethanol permeability $k_{\mathrm{w}, \mathrm{e}}\left(\mathrm{m}^{2}\right)$ can be calculated from Darcy's law as,

$$
k_{\mathrm{w}, \mathrm{e}}=\mu_{\mathrm{w}, \mathrm{e}} \frac{Q}{A} \frac{L}{\Delta P}
$$

in which $\mu_{\mathrm{w}, \mathrm{e}}(\mathrm{Pa} \cdot \mathrm{s})$ is the dynamic viscosity of liquid water or ethanol, $L(\mathrm{~m})$ is the length of flowing path equaling to the thickness of specimen, $A\left(\mathrm{~m}^{2}\right)$ is the area of cross section, and $\Delta P$ $(\mathrm{Pa})$ is the pressure difference between the two opposite circular surfaces. 
For gas permeability testing, the compressibility of inert gas and slippage effect happened in small pores should be taken into account. With the identical steady state permeameter, gas permeability of argon gas is measured at controlled ambient temperature $20^{\circ} \mathrm{C}$. Each totally dried specimen of size $\phi 65 \times 30 \mathrm{~mm}$ is placed inside the permeameter and then subjected to a constant confining pressure $P_{\mathrm{c}}$ of 50 bars to ensure lateral surface air-tight. The inlet gas pressure $P_{\mathrm{i}}$ is regulated and constantly applied on the bottom inflow surface while atmospheric pressure $P_{0}$ is kept on the opposite outflow end. The volume down-flow rate is monitored by a flowmeter of high precision. If relative change of volume flowing rate is less than $2 \%$, a steady state flow is considered to be reached. From the measured steady volume flow rate $Q(\mathrm{~mL} / \mathrm{min})$, the apparent gas permeability $k_{\text {app }}\left(\mathrm{m}^{2}\right)$ considering its high compressibility can be deduced through the wellknown Hagen-Poiseuille relationship [43, 44],

$$
k_{\mathrm{app}}=\frac{2 \mu_{\mathrm{g}} L Q P_{0}}{A\left(P_{\mathrm{i}}^{2}-P_{0}^{2}\right)}
$$

where $\mu_{\mathrm{g}}(\mathrm{Pa} \cdot \mathrm{s})$ is the gas viscosity $\left(2.2 \mathrm{E}-5 \mathrm{~Pa} \cdot \mathrm{s}\right.$ for argon gas at $\left.20^{\circ} \mathrm{C}\right)$. It is well known that apparent permeability $k_{\text {app }}$ is dependent on the inlet pressure due to the gas slippage at small pore walls, which is understood as the Klinkenberg effect [45]. To obtain the intrinsic permeability $k_{\text {int }}$ $\left(\mathrm{m}^{2}\right)$ of porous medium independent of the inlet pressure, the following relationship is further employed [45],

$$
k_{\mathrm{app}}=k_{\mathrm{int}}\left(1+\frac{\beta_{\mathrm{k}}}{P_{\mathrm{m}}}\right), \quad P_{\mathrm{m}}=\frac{P_{\mathrm{i}}+P_{0}}{2}
$$

where $\beta_{\mathrm{k}}$ (bar) is named as Klinkenberg coefficient or slippage factor. In these experimental procedures, the apparent gas permeability $k_{\text {app }}$ for each specimen is measured at four levels of inlet pressure $P_{\mathrm{i}}$ near 10,15, 20 and 25 bars. The intrinsic permeability $k_{\text {int }}$ and Klinkenberg coefficient $\beta_{\mathrm{k}}$ are further regressed from the relationship between apparent permeability $k_{\mathrm{app}}$ and inverse mean pressure $1 / P_{\mathrm{m}}$ through Equation (26). Very high correlation coefficient $R^{2}>0.99$ is always observed for all disk specimens. One typical regression for intrinsic gas permeability $k_{\text {int }}$ is shown in Figure 2a. It is worthy noted that the inlet pressure adopted herein is almost one order of magnitude higher than that recommended in CEMBUREAU method to enhance the volume flow rate of gas [46, 47]. This will be further discussed in following Section 4.4.

According to the above testing methods and procedures, the permeability to liquid water, argon gas and ethanol are measured in sequence on 3 disk specimens of size $\phi 65 \mathrm{~mm} \times 30 \mathrm{~mm}$ from each concrete material, as listed in Table 3 below. As no water flow can be detected under the action of inject pressure of 15 bars in a long time (several days), the liquid water permeability for dense concretes C19 and C29 are too small to measure. However, their water permeability can be 


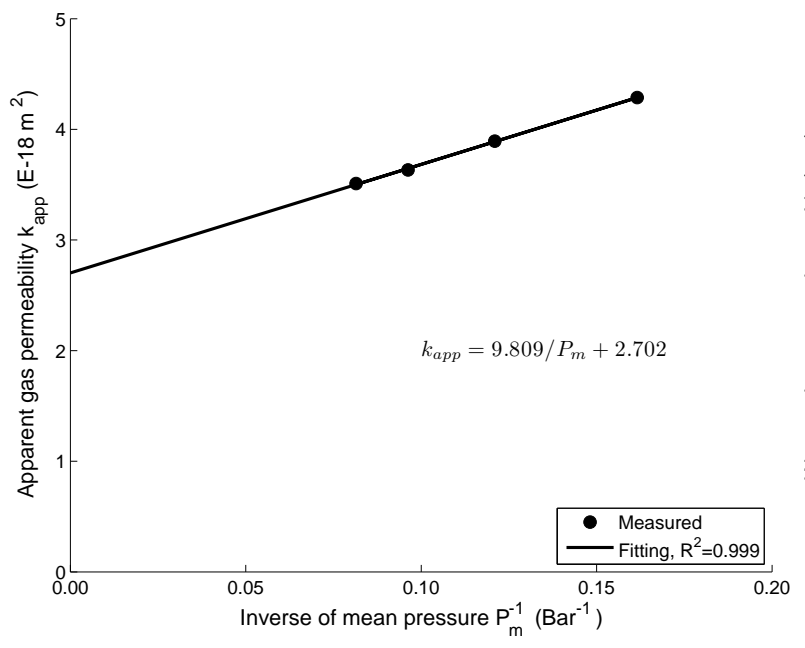

(a) Gas permeability

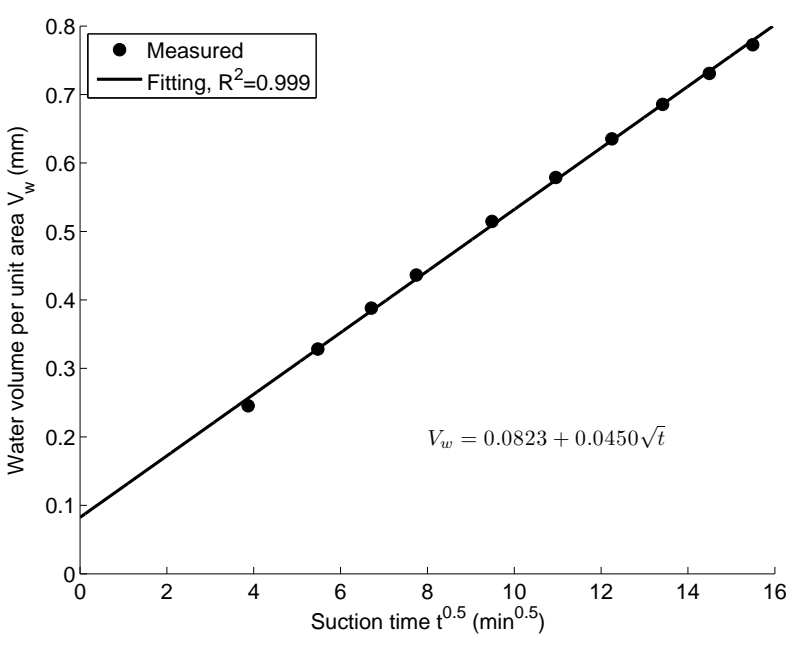

(b) Capillary sorptivity

Figure 2: Fitting of gas permeability and capillary sorptivity for totally dried specimen KS-1 of concrete C39.

indirectly calculated from measured sorptivity and water vapour sorption isotherms, which will be further analyzed in Section 4.3.

\subsection{Preconditioning strategy for unsaturated gas permeability and sorptivity measurements}

After choosing the measurement method for gas permeability, the key of unsaturated gas permeability and following capillary sorptivity measurements is how to prepare the unsaturated concrete specimens of various water content uniformly distributed in its pore space. To measure the gas permeability and capillary sorptivity for unsaturated concrete materials, a procedure of uniformly drying out moisture is an unavoidable necessity. There are various preconditioning methods adopted in literature to attain this goal. In brief, they can be categorized into two kinds, the accelerated drying-equilibrium method [8, 19, 48, 49] and the natural sorption method [50, 51]. By the accelerated drying-equilibrium method, the specimen is first dried to target water content and then sealed for a period to make water uniformly distributed at a relative high temperature. While by the natural sorption method, the specimen is put into a closed ambience of certain relative humidity controlled constant until mass stabilization. Since the natural sorption method is remarkably time-consuming, the accelerated drying-equilibrium method is widely adopted.

To prepare unsaturated concrete specimens for gas permeability and capillary sorptivity measurements, a self-scaled drying-equilibrium procedure is designed and implemented. The critical idea is that the time cost by partly drying to pre-designed water saturation degree plus the equilibrium time required to attain uniform water distribution is equal to the time required by totally 
Table 3: Measured permeability to liquid water, gas and ethanol for three concrete materials

\begin{tabular}{|c|c|c|c|c|c|}
\hline \multirow[t]{2}{*}{ Materials } & Water permeability $\left(\mathrm{m}^{2}\right)$ & \multicolumn{2}{|c|}{ Argon permeability $\left(\mathrm{m}^{2}\right)$} & \multicolumn{2}{|c|}{ Ethanol permeability $\left(\mathrm{m}^{2}\right)$} \\
\hline & & $1.33 \mathrm{E}-18$ & & $1.61 \mathrm{E}-18$ & \\
\hline \multirow[t]{3}{*}{$\mathrm{C} 19$} & \multirow[t]{2}{*}{ Too small to measure } & $1.16 \mathrm{E}-18$ & $1.29 \mathrm{E}-18$ & $1.30 \mathrm{E}-18$ & $1.51 \mathrm{E}-18$ \\
\hline & & $1.39 \mathrm{E}-18$ & & $1.61 \mathrm{E}-18$ & \\
\hline & \multirow{3}{*}{ Too small to measure } & $2.60 \mathrm{E}-18$ & & $2.71 \mathrm{E}-18$ & \\
\hline \multirow[t]{3}{*}{$\mathrm{C} 29$} & & $3.07 \mathrm{E}-18$ & $2.88 \mathrm{E}-18$ & $3.05 \mathrm{E}-18$ & $2.86 \mathrm{E}-18$ \\
\hline & & $2.96 \mathrm{E}-18$ & & $2.83 \mathrm{E}-18$ & \\
\hline & $2.71 \mathrm{E}-20$ & $4.27 \mathrm{E}-18$ & & $3.49 \mathrm{E}-18$ & \\
\hline \multirow[t]{2}{*}{ C39 } & $3.52 \mathrm{E}-20$ & $5.70 \mathrm{E}-18$ & $5.26 \mathrm{E}-18$ & $5.72 \mathrm{E}-18$ & $4.92 \mathrm{E}-18$ \\
\hline & $4.04 \mathrm{E}-20$ & $5.82 \mathrm{E}-18$ & & $5.57 \mathrm{E}-18$ & \\
\hline
\end{tabular}

drying to constant mass. The drying and following equilibrium experiments are carried out under the same condition with moderate temperature $60^{\circ} \mathrm{C}$ to shorten the time cost and diminish obvious alteration of micro-structure.

To experimentally investigate the gas permeability and capillary sorptivity for unsaturated concrete materials, 8 disks of size $\phi 65 \mathrm{~mm} \times 50 \mathrm{~mm}$ are wet sawed and immersed in lime-saturated water for another 7 days to make it initially saturated. To ensure one dimensional fluid flow in sorptivity measurement, the curved surface of each disk is carefully covered with epoxy resin. After evaluating the capillary porosity for each concrete material (as shown in Table 1), the predesigned mass reduction for 6 specimens (denoted as KS-1/2/3/4/5/6) with different target water saturation degrees uniformly located in the range $[0,1]$ can be roughly calculated. After saturation, all specimens are put in a oven-drying chamber to be partly dried under temperature $60^{\circ} \mathrm{C}$. In the drying process, their mass are regularly monitored. Once the target mass reduction for any specimen is met, the specimen is wrapped by aluminum foil to stop water evaporation and then still stored in the chamber until the last 2 specimens (denoted as KS-7/8) are totally dried to constant mass (relative change of mass is less than $0.1 \%$ in 7 days). At that time, the water content in the wrapped concrete specimens with various saturation degrees are thought to be uniformly stored in its pore space. By this well-designed drying-equilibrium procedure, it takes about 10 weeks to prepare partially saturated specimens. After preconditioning, all specimens are cooled down to room temperature for the first cycle (1st) measurements of gas permeability and following capillary sorptivity. In this self-scale preconditioning scheme, the required equilibrium time span is scaled by himself without a priori determination. The effect brought by this carefully designed self-scale preconditioning is very good, which will be further discussed in Section 4.4. 
Table 4: Measured sorptivity and gas permeability for partially saturated and totally dried specimens for concrete C19.

\begin{tabular}{|c|c|c|c|c|c|c|c|c|c|}
\hline \multicolumn{2}{|c|}{ Property $^{*}$} & KS-1 & KS-2 & KS-3 & $\mathrm{KS}-4$ & KS-5 & KS-6 & $\mathrm{KS}-7$ & $\mathrm{KS}-8$ \\
\hline \multicolumn{2}{|c|}{$\theta_{\mathrm{s}}$} & 6.02 & 6.59 & 7.00 & 7.45 & 7.40 & 7.98 & 8.15 & 7.47 \\
\hline \multirow{4}{*}{$1 \mathrm{st}$} & $\omega$ & 59.41 & 54.63 & 44.89 & 34.78 & 21.14 & 11.48 & 0 & 0 \\
\hline & $k_{\text {int }}$ & $1.03 \mathrm{E}-20$ & $6.25 \mathrm{E}-20$ & $1.25 \mathrm{E}-19$ & $5.96 \mathrm{E}-19$ & 7.10E-19 & 8.43E-19 & $1.47 \mathrm{E}-18$ & 8.39E-19 \\
\hline & $\beta_{\mathrm{k}}$ & 24.16 & 9.67 & 10.60 & 5.25 & 4.54 & 5.27 & 4.77 & 4.38 \\
\hline & $S$ & 0.0163 & 0.0193 & 0.0206 & 0.0311 & 0.0443 & 0.0383 & 0.0349 & 0.0277 \\
\hline \multirow{4}{*}{ 2nd } & $\omega$ & 0 & 0 & 0 & 0 & 0 & 0 & 13.94 & 16.00 \\
\hline & $k_{\text {int }}$ & $3.73 \mathrm{E}-19$ & 7.41E-19 & 8.97E-19 & $1.51 \mathrm{E}-18$ & $1.24 \mathrm{E}-18$ & $1.14 \mathrm{E}-18$ & $1.38 \mathrm{E}-18$ & $6.90 \mathrm{E}-19$ \\
\hline & $\beta_{\mathrm{k}}$ & 7.12 & 5.67 & 7.02 & 4.22 & 5.21 & 5.42 & 5.30 & 9.07 \\
\hline & $S$ & 0.0332 & 0.0352 & 0.0285 & 0.0402 & 0.0364 & 0.0323 & 0.0206 & 0.0164 \\
\hline
\end{tabular}

* 1 st and 2 nd denote the first and second period in abbreviation. And the unit for volumetric water content $\theta_{\mathrm{s}}$ at saturation, saturation degree $\omega$, intrinsic gas permeability $k_{\mathrm{int}}$, Klinkenberg coefficient $\beta_{\mathrm{k}}$ and sorptivity $S$ is (\%), (\%), $\mathrm{m}^{2}$, bar and $\mathrm{mm} / \mathrm{min}^{0.5}$, respectively.

After the first cycle measurements of gas permeability and sorptivity, the water content of all specimen are altered. To obtain relative gas permeability for each individual specimen, right after sorptivity measurement the six partially saturated specimens KS-1/2/3/4/5/6 are put into the over-drying chamber to dry again until constant mass under temperature $60^{\circ} \mathrm{C}$. While another two totally dried specimens KS-7/8 are wrapped with aluminum foil and then put into the chamber to equilibrate. After all the 6 unsaturated specimens KS-1/2/3/4/5/6 are totally dried, equilibrium states for another 2 specimens KS-7/8 are thought to be reached. Then, the second cycle (2nd) measurements of gas permeability and capillary sorptivity are carried out. Together with the results from the first cycle measurements, the gas permeability and capillary sorptivity at both partially saturated and totally dried states can be measured for each specimen, as listed in Table 4-6. Then, the relative gas permeability $k_{\mathrm{rg}}$ and relative capillary sorptivity $S_{\mathrm{r}}$ can be individually calculated for all specimens. This will help conquer the inherent variation of transport properties for concrete materials.

\subsection{Measurement of capillary sorptivity}

Right after gas permeability test, the capillary sorptivity measurement is carried out on disk specimen by surface suction method [5]. The initial mass for each cylindrical specimen is weighted by an electronic balance to $0.001 \mathrm{~g}$. It is then put in a water tray with only about $3 \mathrm{~mm}$ immersed in the liquid water. At elapsed time $t=15,30,45,60,90,120,150,180,210,240$ minutes, the sample is moved out from the water tray, quickly wiped with pieces of paper to remove free water 
Table 5: Measured sorptivity and gas permeability for partially saturated and totally dried specimens for concrete C29.

\begin{tabular}{|c|c|c|c|c|c|c|c|c|c|}
\hline \multicolumn{2}{|c|}{ Property* } & KS-1 & KS-2 & $\mathrm{KS}-3$ & KS-4 & KS-5 & KS-6 & KS-7 & KS-8 \\
\hline \multicolumn{2}{|c|}{$\theta_{\mathrm{s}}$} & 8.00 & 8.71 & 8.73 & 8.33 & 8.89 & 8.79 & 9.57 & 10.66 \\
\hline \multirow{4}{*}{$1 \mathrm{st}$} & $\omega$ & 70.06 & 62.84 & 43.37 & 32.49 & 23.09 & 6.86 & 0 & 0 \\
\hline & $k_{\text {int }}$ & $1.61 \mathrm{E}-20$ & $1.01 \mathrm{E}-19$ & $2.96 \mathrm{E}-19$ & $5.95 \mathrm{E}-19$ & 8.83E-19 & $1.55 \mathrm{E}-18$ & $1.84 \mathrm{E}-18$ & $2.49 \mathrm{E}-18$ \\
\hline & $\beta_{\mathrm{k}}$ & 25.21 & 10.93 & 9.46 & 4.55 & 5.62 & 3.67 & 3.69 & 3.14 \\
\hline & $S$ & 0.0120 & 0.0156 & 0.0375 & 0.0387 & 0.0427 & 0.0417 & 0.0329 & 0.0371 \\
\hline \multirow{4}{*}{ 2nd } & $\omega$ & 0 & 0 & 0 & 0 & 0 & 0 & 16.30 & 8.76 \\
\hline & $k_{\text {int }}$ & $1.45 \mathrm{E}-18$ & $1.54 \mathrm{E}-18$ & $1.85 \mathrm{E}-18$ & $1.56 \mathrm{E}-18$ & $1.80 \mathrm{E}-18$ & $1.91 \mathrm{E}-18$ & $1.48 \mathrm{E}-18$ & $2.02 \mathrm{E}-18$ \\
\hline & $\beta_{\mathrm{k}}$ & 3.71 & 4.55 & 3.87 & 4.49 & 4.01 & 3.63 & 4.33 & 3.93 \\
\hline & $S$ & 0.0338 & 0.0312 & 0.0437 & 0.0318 & 0.0160 & 0.0127 & 0.0065 & 0.0177 \\
\hline
\end{tabular}

* 1 st and 2nd denote the first and second period in abbreviation. And the unit for volumetric water content $\theta_{\mathrm{s}}$ at saturation, saturation degree $\omega$, intrinsic gas permeability $k_{\mathrm{int}}$, Klinkenberg coefficient $\beta_{\mathrm{k}}$ and sorptivity $S$ is (\%), (\%), $\mathrm{m}^{2}$, bar and $\mathrm{mm} / \mathrm{min}^{0.5}$, respectively.

Table 6: Measured sorptivity and gas permeability for partially saturated and totally dried specimens for concrete C39.

\begin{tabular}{|c|c|c|c|c|c|c|c|c|c|}
\hline \multicolumn{2}{|c|}{ Property* } & $\mathrm{KS}-1$ & $\mathrm{KS}-2$ & KS-3 & KS-4 & KS-5 & KS-6 & $\mathrm{KS}-7$ & $\mathrm{KS}-8$ \\
\hline \multicolumn{2}{|c|}{$\theta_{\mathrm{s}}$} & 9.82 & 10.86 & 11.90 & 12.71 & 11.25 & 11.35 & 11.67 & 14.02 \\
\hline \multirow{4}{*}{$1 \mathrm{st}$} & $\omega$ & 71.40 & 61.55 & 50.85 & 46.28 & 24.66 & 9.03 & 0 & 0 \\
\hline & $k_{\text {int }}$ & $2.27 \mathrm{E}-20$ & $1.64 \mathrm{E}-19$ & $6.15 \mathrm{E}-19$ & 7.79E-19 & $1.88 \mathrm{E}-18$ & $2.58 \mathrm{E}-18$ & $3.16 \mathrm{E}-18$ & 4.14E-18 \\
\hline & $\beta_{\mathrm{k}}$ & 27.00 & 8.54 & 5.59 & 4.34 & 4.09 & 3.78 & 3.70 & 3.33 \\
\hline & $S$ & 0.0139 & 0.0230 & 0.0397 & 0.0398 & 0.0618 & 0.0430 & 0.0460 & 0.0590 \\
\hline \multirow{4}{*}{ 2nd } & $\omega$ & 0 & 0 & 0 & 0 & 0 & 0 & 13.70 & 19.94 \\
\hline & $k_{\text {int }}$ & $2.70 \mathrm{E}-18$ & $3.15 \mathrm{E}-18$ & $5.10 \mathrm{E}-18$ & $4.18 \mathrm{E}-18$ & 3.63E-18 & $3.88 \mathrm{E}-18$ & $2.52 \mathrm{E}-18$ & $3.04 \mathrm{E}-18$ \\
\hline & $\beta_{\mathrm{k}}$ & 3.63 & 3.60 & 2.85 & 3.33 & 3.28 & 3.18 & 3.89 & 3.89 \\
\hline & $S$ & 0.0450 & 0.0508 & 0.0628 & 0.0421 & 0.0317 & 0.0598 & 0.0222 & 0.0395 \\
\hline
\end{tabular}

* 1 st and 2nd denote the first and second period in abbreviation. And the unit for volumetric water content $\theta_{\mathrm{s}}$ at saturation, saturation degree $\omega$, intrinsic gas permeability $k_{\text {int }}$, Klinkenberg coefficient $\beta_{\mathrm{k}}$ and sorptivity $S$ is (\%), (\%), $\mathrm{m}^{2}$, bar and $\mathrm{mm} / \mathrm{min}^{0.5}$, respectively. 
on the bottom surface, and then weighted to obtain the absorbed water mass $m_{\mathrm{W}}(\mathrm{g})$. Right after weighting, the specimen is re-set in the water tray to continue water absorption. All these operations should be finished in 30 seconds to eliminate possible error due to the change of boundary condition during weighting. From the measured water mass absorption $m_{\mathrm{w}}$ at different time, the capillary sorptivity $S\left(\mathrm{~mm} / \mathrm{min}^{0.5}\right)$ can be obtained through linear fitting the relationship between absorbed water volume per unit area $V_{\mathrm{w}}(\mathrm{mm})$ and elapsed time $t(\mathrm{~min})$ to the Equation (3). One typical fitting of capillary sorptivity is shown in Figure $2 \mathrm{~b}$. Very high correlation coefficients $R^{2}$ are always observed for all concrete specimens.

After the gas permeability measurement in the first and second cycles, the capillary sorptivity are measured on one identical circular surface for each specimen at both partially saturated and totally dried statuses, as listed in Table 4-6. It is noted that the sorptivity measurement in the first cycle may affect the micro-structure of partially and totally dried specimens due to their contact with liquid water. It brings some unexpected effects to the sorptivity measured in the second cycle, which will be further discussed in Section 4.4.

\section{Results and discussion}

\subsection{Desorption and adsorption isotherms}

The desorption and adsorption isotherms listed in Table 2 are plotted in Figure 3 a to show the relationship between equilibrated water mass content $w$ and relative humidity $R H$. Each plot of the curves in Figure $3 \mathrm{a}$ is the average value of experimental data obtained on two disk specimens for each concrete material. The water mass content at $R H=1$ is represented by that at fully saturation state. Furthermore, the desorption and adsorption isotherms are also translated into water retention curve to give the capillary pressure head $h_{\mathrm{c}}$ at various saturation degree $\omega$, as shown in Figure $3 \mathrm{~b}$.

In Figure 3a, the hysteresis effect between first cycle desorption and adsorption is obviously significant for all three concrete materials. The difference of water mass content between desorption and adsorption processes is remarkable in the whole range of relative humidity and tends to be smaller when relative humidity becomes higher. According to the well-known Kelvin equation, the critical pore size below which micro-pores are filled with liquid water is the same under identical relative humidity. However, the pore volume actually occupied by liquid water is absolutely different in desorption and adsorption processes. This widely observed phenomenon is attributed to the inkbottle effect for complex pore structure and the possible different liquid-vapour interface $[18,30]$. As relative humidity rises, the water mass content increases quickly. In adsorption process, the water contents for all three concrete materials of different $\mathrm{W} / \mathrm{C}$ ratio are very close when the relative humidity is below $59 \%$, beyond which the gap between them becomes broaden. 


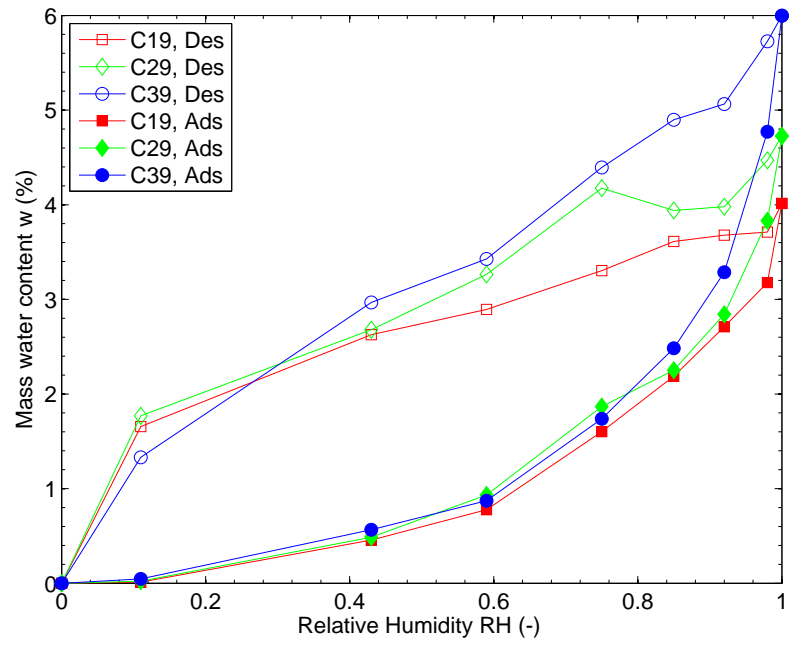

(a) Desorption and adsorption isotherms

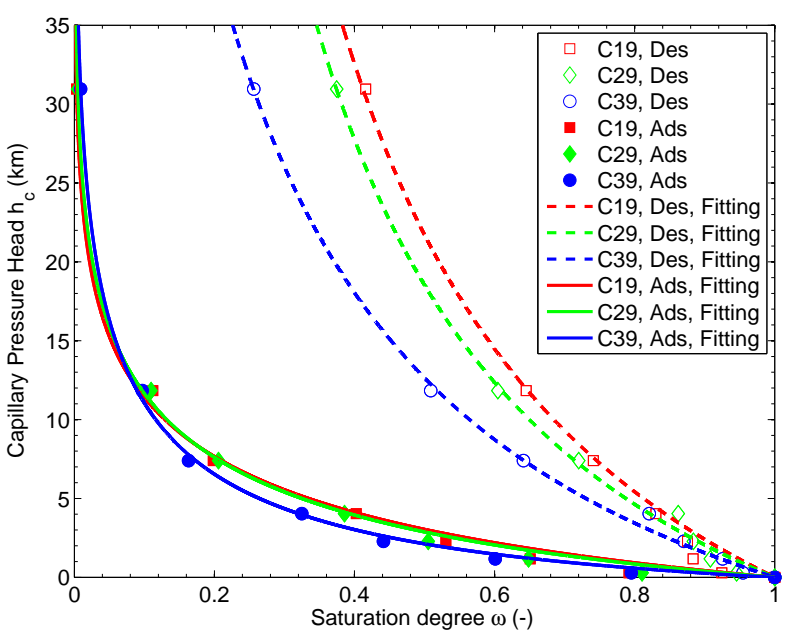

(b) Water retention curve

Figure 3: The first cycle desorption and adsorption isotherms and corresponding water retention curve.

Table 7: The fitting parameters $\alpha, \beta$ in Zhou model for both desorption and adsorption processes.

\begin{tabular}{ccccc}
\hline Process & Materials & $\alpha(-)$ & $\beta\left(\mathrm{km}^{-1}\right)$ & $R^{2}(-)$ \\
\hline \multirow{4}{*}{ Desorption } & C19 & $1.222 \mathrm{E}+03$ & $3.767 \mathrm{E}-05$ & 0.9968 \\
& C29 & $5.164 \mathrm{E}+02$ & $1.045 \mathrm{E}-04$ & 0.9969 \\
& C39 & $3.978 \mathrm{E}+00$ & $1.774 \mathrm{E}-02$ & 0.9982 \\
\hline \multirow{4}{*}{ Absorption } & C19 & $1.437 \mathrm{E}+00$ & $1.739 \mathrm{E}-01$ & 0.9973 \\
& C29 & $1.784 \mathrm{E}+00$ & $1.545 \mathrm{E}-01$ & 0.9985 \\
& C39 & $3.804 \mathrm{E}+00$ & $1.099 \mathrm{E}-01$ & 0.9991 \\
\hline
\end{tabular}

The same tendency can be also observed in the desorption process. It is indicated that there is only a little difference between the small pore structures for all three concrete materials. However, the difference about big pore structure is more observable due to their different water to cement ratios. Because of the significant hysteresis effect, the water transport properties will be obviously different in drying (desorption) and wetting (adsorption) processes [52].

Quantitatively, the Zhou model Equation (16) with two fitting parameters $\alpha$ and $\beta$ is employed herein to describe the water retention data in both desorption and adsorption processes, as shown in Figure 3b. The regressed empirical parameters $\alpha$ and $\beta$ are also listed in Table 7. Very high correlation coefficient $R^{2}>0.99$ are obtained for both desorption and adsorption processes, indicating that the Zhou model is well capable to quantify the water retention characteristics during either desorption or adsorption for cement-based materials. 
As Zhou model is successfully applied to describe the water retention curve for cement-based materials, the capacity function can be then explicitly calculated from Equation (17). After obtaining the empirical parameters $\alpha$ and $\beta$ by nonlinear regression, the capacity function in desorption and adsorption processes for all three concrete materials can be calculated, as displayed in Figure 4. It can be seen that the capacity functions are monotonically increasing with respect to saturation degree, indicating that more water content will be released or absorbed at higher saturation degree in either drying or wetting process. When the saturation degree or relative humidity is very low, the variation of water content is rather limited even capillary pressure head is greatly changed. In another aspect, it is easy to know from Figure 4 that the derived capacity function for adsorption process is about 5 times higher than that for desorption process. Under the same alteration of capillary pressure head, the water content absorbed in adsorption is about 4 times more than that released in desorption. From this consideration, it can be concluded that cementbased materials can easily absorb liquid water but rather difficult to release it due to complex pore structure.

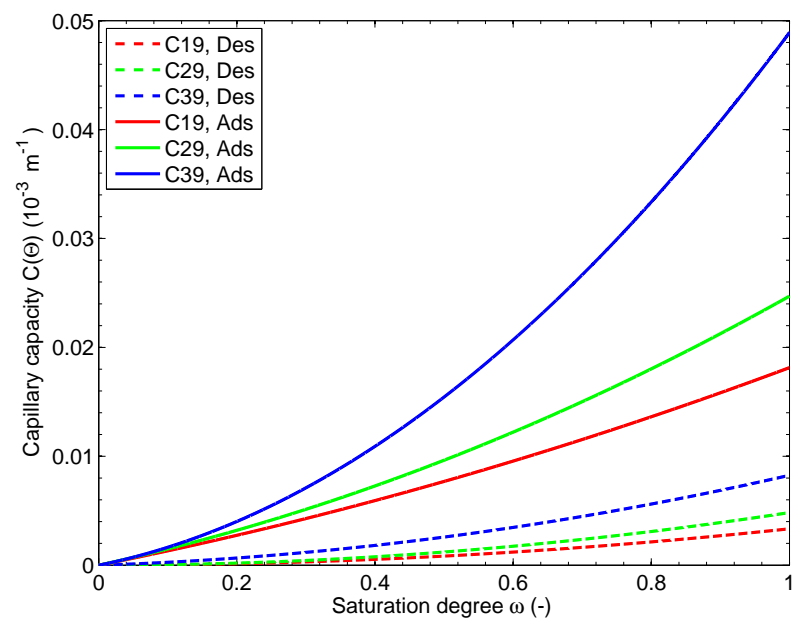

Figure 4: The predicted capacity functions in both desorption and adsorption processes.

\subsection{Indirect evaluation of hydraulic diffusivity from sorptivity}

The key to determine hydraulic diffusivity of exponential law is to evaluate the shape parameter $n_{0}$ and initial hydraulic diffusivity $D_{0}$ in Equation (4), which can be achieved by nonlinearly fitting the relationship between normalized sorptivity $S / \theta_{\mathrm{s}}$ and initial saturation degree $\omega_{\mathrm{i}}$ through Equation (14). From the volumetric water content $\theta_{\mathrm{s}}$ at saturation and sorptivity $S$ measured in both 1 st and 2 nd periods, as listed in Table $4-6$, the normalized sorptivity $S / \theta_{\mathrm{s}}$ are computed 


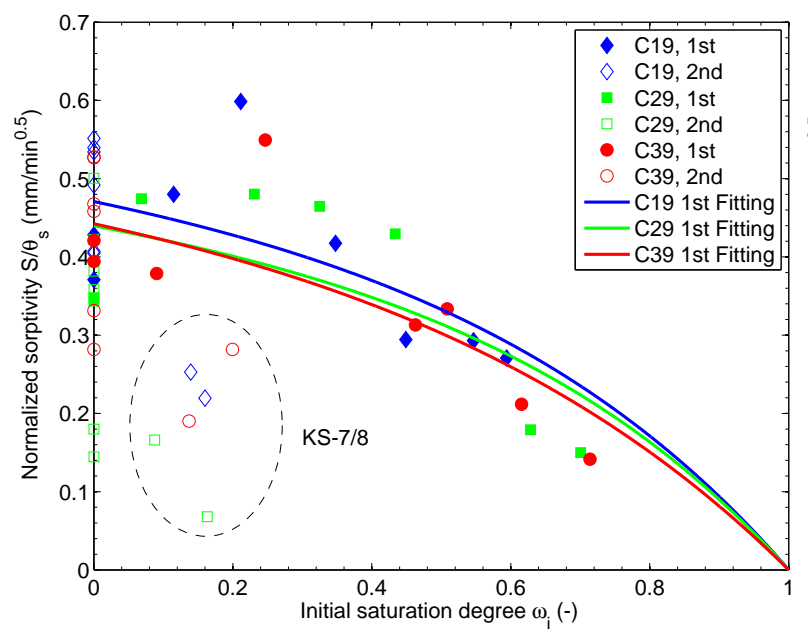

(a) Zhou method

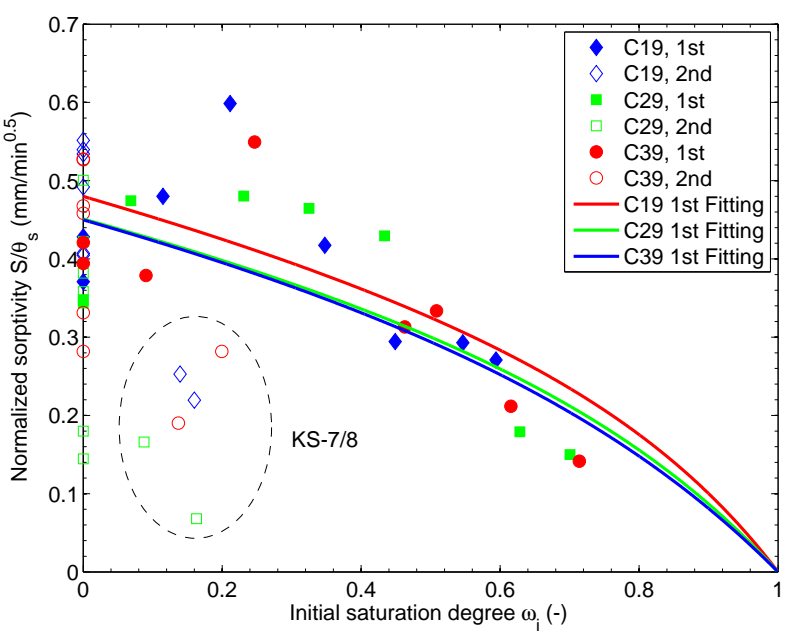

(b) Parlange method

Figure 5: The indirectly assessed shape parameter $n_{0}$ from measured sorptivity during 1 st period for three concretes.

Table 8: The fitted parameters $n_{0}, D_{0}$ of hydraulic diffusivity and predicted water permeability.

\begin{tabular}{ccccc|cc}
\hline Method & Materials & $n_{0}(-)$ & $D_{0}\left(\mathrm{~mm}^{2} / \mathrm{min}\right)$ & $R^{2}(-)$ & $D(\omega=1)$ & $k_{\mathrm{sw}}\left(\mathrm{m}^{2}\right)$ \\
\hline \multirow{4}{*}{ Zhou } & C19 & 7.266 & $6.620 \mathrm{E}-04$ & 0.4458 & 0.947 & $2.599 \mathrm{E}-20$ \\
& C29 & 7.652 & $4.180 \mathrm{E}-04$ & 0.5301 & 0.880 & $3.287 \mathrm{E}-20$ \\
& C39 & 6.200 & $1.412 \mathrm{E}-03$ & 0.6580 & 0.696 & $5.146 \mathrm{E}-20$ \\
\hline \multirow{4}{*}{ Parlange } & C19 & 7.347 & $5.850 \mathrm{E}-04$ & 0.4110 & 0.908 & $2.490 \mathrm{E}-20$ \\
& C29 & 5.727 & $2.083 \mathrm{E}-03$ & 0.4828 & 0.640 & $2.389 \mathrm{E}-20$ \\
& C39 & 4.713 & $4.809 \mathrm{E}-03$ & 0.6366 & 0.536 & $3.961 \mathrm{E}-20$ \\
\hline
\end{tabular}

and plotted with respect to corresponding initial saturation degree $\omega_{\mathrm{i}}$ in Figure 5. Due to the significant microstructural alteration of surface layer for concrete specimens after the contact with liquid water in the 1st period (it will be discussed in the next paragraph), the normalized capillary sorptivity $S / \theta_{\mathrm{S}}$ measured in the 2nd period shows unexpected deviation from that measured in the 1st period, and thus are excluded in the following nonlinear regression. Therefore, only the normalized sorptivity $S / \theta_{\mathrm{s}}$ measured in the 1st period are fitted through Equation (14) in the sense of least-square to obtain the shape parameter $n_{0}$ and initial hydraulic diffusivity $D_{0}$, as listed in following Table 8.

From Figure 5, the evolution of normalized sorptivity $S / \theta_{\mathrm{s}}$ with respect to initial water saturation degree can be roughly captured by the theoretical formula Equation (14) from both Zhou and Parlange methods. The shape parameters $n_{0}$ derived from both Zhou and Parlange meth- 


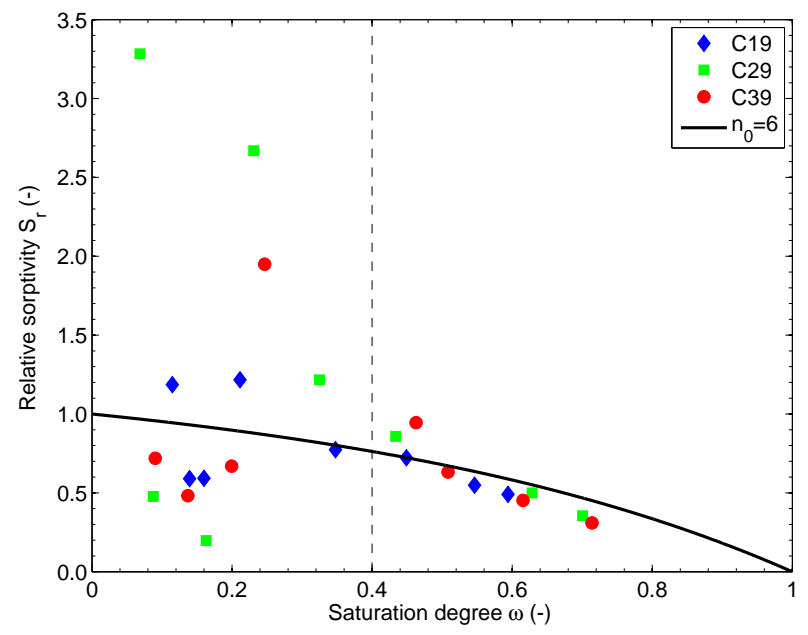

Figure 6: The measured relative sorptivity for three concretes and theoretical curve with shape parameter $n_{0}=6$.

ods are all near typical value about 6.0 for cement-based materials [3]. However, the correlation coefficient $R^{2}$ is relatively small due to great scattering of measured sorptivity for unsaturated specimen with low initial saturation degree. In the 2nd period, the sorptivity measured on the totally dried specimens $\mathrm{KS}-1 / 2 / 3 / 4 / 5 / 6$ once contact with liquid water in 1 st period are greatly scattered in a large range. It is also emphasized that the capillary sorptivity for partially saturated specimens KS-7/8 that have been wetted once from totally dry state deviate far from the main relationship between normalized sorptivity and initial saturation degree. Rewetting these specimens allows dehydrated material and possible unhydrated clinker to rehydrate, which probably closes shrinkage-induced micro-cracks and blocks micro-pores in the immediate vicinity of the rehydration sites [53-55]. Moreover, the water in the interlayer space once removed in the 1st period does not completely re-saturated the pore space in the following sorptivity test [56]. These kinds of microstructure alteration dominate over the shrinkage-induced micro-cracking and remarkably reduce the rate of capillary transport of specimens KS-7/8. To further investigate the influence of contact with liquid water, the measured relative sorptivity $S_{\mathrm{r}}$ for each specimen is calculated and plotted in Figure 6. The theoretical relative sorptivity is also calculated through Equation (15) with shape parameter $n_{0}=6$, as shown in Figure 6. It is easily inferred that the contact with liquid water have caused some changes to the microstructure of partially dried concrete materials with initial saturation degree less than 0.4 . From these considerations, the capillary sorptivity measured in the 2nd period are not taken into account when fitting the relationship between normalized sorptivity and initial saturation degree through Equation (14) to obtain shape parameter $n_{0}$ and initial hydraulic diffusivity $D_{0}$.

As an important transport property, the hydraulic diffusivity of exponential law can be deter- 
mined by Equation (4) after indirectly evaluating the shape parameter $n_{0}$ and initial hydraulic diffusivity $D_{0}$ from sorptivity, as displayed in Figure $7 \mathrm{a}$. In this figure, one can see that the hydraulic diffusivity $D(\omega)$ is very sensitive to saturation degree. It increases greatly when water saturation is larger than about 0.8 due to the large shape parameter near 6 . When saturation degree $\omega$ is smaller than 0.8 , the hydraulic diffusivity from either Zhou or Parlange method is very close for all three concrete materials, which is attributed to their similar microstructure of small pores. Beyond saturation degree about 0.8 , the hydraulic diffusivity for concrete C19 of the smallest W/C ratio is biggest while $\mathrm{C} 39$ with the highest $\mathrm{W} / \mathrm{C}$ ratio is smallest. It is surprised to find that the calculated hydraulic diffusivity for these three concrete materials decreases with increasing water to cement ratio, which significantly disagrees with some experimental studies [3, 57]. Actually, it is mathematically reasonable since the hydraulic diffusivity $D(\omega)$ is determined by water permeability $k_{\mathrm{w}}(\omega)$ together with capacity function $C(\omega)$ through Equation (18). From the clear physical meaning of water permeability, it is easy to know that it always increases with increasing water content for any porous material. Usually, concrete with higher water to cement ratio and thus higher capillary porosity has higher conductivity at the same saturation degree. However, the capacity function $C(\omega)$ presents various dependence on water saturation due to the complicated relationship between capillary pressure head and water content [21, 58, 59]. As a results, as shown in Equation (18), the hydraulic diffusivity $D(\omega)$ proportional to the water permeability $k_{\mathrm{w}}(\omega)$ divided by complicated capacity function $C(\omega)$ possibly decreases with increase in water saturation degree and even presents various relationship with it $[60,61]$. Although the hydraulic diffusivity for general soils and cementitious materials can be empirically quantified by exponential law or power law $[32,62]$, there is no theoretical evidence giving that it must be monotonic function with respect to water content and capillary porosity etc.

It is worth noting that the physical significance for hydraulic diffusivity is also rather ambiguous $[3,63]$. One should always bear in mind that, hydraulic diffusion is actually a liquid water flowing process under the action of capillary pressure gradient due to saturation gradient rather than Brownian motion. Although the water flow in unsaturated porous material can be quantified by a governing equation mathematically similar to that for pure diffusion, the water flow is physically caused by capillary pressure rather than gradient of liquid water content. As a result, the physical significance for hydraulic diffusivity is rather ambiguous and should be interpreted very carefully. In another aspect, the moisture transport is a rather complicated process including liquid water flow, vapour diffusion as well as capillary evaporation and condensation [8]. Various testing methods adopted to measure moisture diffusion coefficient may involve different moisture transport process, and thus yield different diffusion coefficient [18]. From these above considerations, 


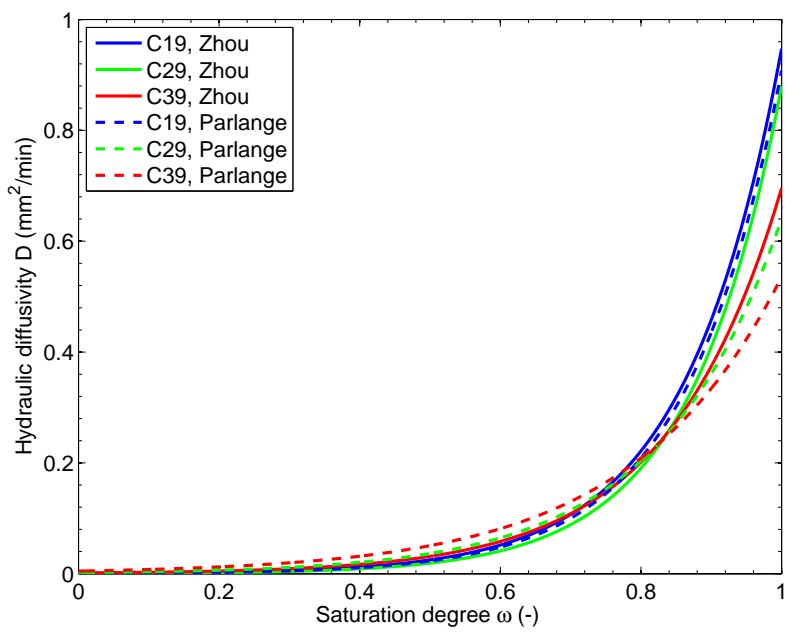

(a) Hydraulic diffusivity the durability potential for cement-based materials

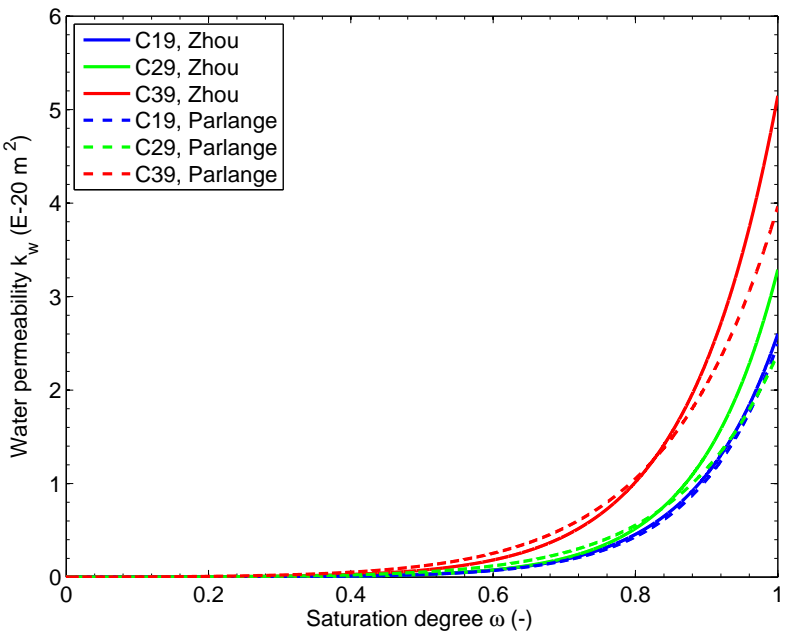

(b) Water premeability

Figure 7: The indirectly predicted hydraulic diffusivity and water permeability for three concretes.

hydraulic diffusivity without clear physical significance is not a good transport property indicating

\subsection{Indirect assessment of water permeability}

Theoretically, unsaturated water permeability $k_{\mathrm{W}}(\omega)$ can be evaluated from capacity function $C(\omega)$ and hydraulic diffusivity $D(\omega)$ through their relationship, which have been determined from water vapour sorption isotherms and sorptivity measured on unsaturated concrete specimens. Since the cylinder specimen is subjected to a wetting process in sorptivity measurement, only the water retention curve and thus capacity function obtained in adsorption process (wetting) is adopted to calculate water permeability through Equation (18), as displayed in Figure 7b. The corresponding water permeability $k_{\mathrm{sw}}$ at saturation states are also listed in Table 8. Importantly, great attention should be paid to the unit of all quantities involved in Equation (18) when calculating unsaturated water permeability.

More information about Zhou and Parlange methods can be obtained by comparing the unsaturated water permeability in Figure $7 \mathrm{~b}$, predicted water permeability in Table 8 as well as the measured permeability to different fluids in Table 3. The first sight from Figure $7 \mathrm{~b}$ is that the water permeability for all three concrete materials is very sensitive to saturation degree especially when saturation degree is higher than 0.8 , which is very common for concrete materials under real service. This is rather similar to the behavior of hydraulic diffusivity with respect to water saturation. Secondly, the water permeability predicted from either Zhou method or Parlange method 
is larger than measured water permeability for concrete C39 but at the same order of magnitude. The predicted water permeability is over-estimated due to the shrinkage micro-cracking induced by moderate drying in sorptivity measurement and water vapour sorption experiment $[53,56,64]$. It is also reported that the water permeability measured by steady flow method may be underestimated because of the self-sealing effect $[3,65]$ and dissatisfaction of full saturation even under high inlet pressure $[14,66]$. As a results, the broad gap between predicted and experimentally measured water permeability is observed. It is also highlighted that, although the saturated water permeability for dense concretes C19 and C29 cannot be experimentally measured by steady state permeameter, they can be indirectly predicted from measured sorptivity and water vapour sorption isotherms. Thirdly, the measured permeability to argon gas and ethanol in Table 3 are very similar and almost 2 orders of magnitude higher than measured and predicted water permeability. It agrees very well with the reported experimental results in published work [14]. Finally, since concrete materials C19, C29 and C39 are of increasing water to cement ratio, it can be judged from common sense that the permeability for them will be increasing in this sequence, which is also verified from the experimental results of their permeability to argon gas and ethanol in Table 3. However, in Table 8 only the saturated water permeability predicted from Zhou method rather than Parlange method agrees well with this judgment. Although the Parlange method gives better saturated water permeability for concrete C39, it cannot distinguish the obvious difference between the water permeability for dense concretes C19 and C29, which can be inferred from the measured permeability to argon and ethanol for them. From the above considerations, it can be reasonably concluded that Zhou method is good at predicting water permeability and performs better than Parlange method. Therefore, only the Zhou method will be taken into account in the following analysis.

\subsection{Relative permeability to water and gas}

After determining the shape parameter $n_{0}$ and fitting parameter $\alpha$, the relative permeability to water and gas $k_{\mathrm{rw}, \mathrm{rg}}$ can be further evaluated for all three concrete materials through Equations (20) and (21), as shown in Figure 8a and Figure 8b. The gas permeability measured for the three concretes concerned herein and another two concrete materials CEMI / CEMV reported in another publication [50] are also displayed in Figure 8a. Moreover, the gas permeability reported for some other cement-based materials including BO, BH [18, 30, 67], C48 of water to cement ratio 0.48 [19] and C50 of water to cement ratio 0.50 [49] are also collected and displayed in Figure $8 \mathrm{~b}$. Due to the difficulty of measuring unsaturated permeability, only the relative water permeability for concrete C50 reported in reference [49] are collected and discussed herein. To 
Table 9: Measurement methods of relative gas permeability for various cement-based materials

\begin{tabular}{ccc|ccc}
\hline Method & \multicolumn{2}{c|}{ Tri-axial permeameter } & \multicolumn{3}{c}{ CEMBUREAU method } \\
\hline Material & C19, C29, C39 & CEMI, CEMV [50] & BO, BH [18] & C48 [19] & C50 [49] \\
W/C $(-)$ & $0.19,0.29,0.39$ & $0.43,0.39$ & $0.43,0.37$ & 0.48 & 0.50 \\
MSA (mm) & 12 & 12 & 20 & 20 & 25 \\
Specimen & $\phi 65 \times 50 \mathrm{~mm}$ & $\phi 37.5 \times 30 \mathrm{~mm}$ & $\phi 150 \times 50 \mathrm{~mm}$ & $\phi 150 \times 50 \mathrm{~mm}$ & $\phi 50-150 \times 50 \mathrm{~mm}$ \\
$P_{\mathrm{c}}$ (bar) & 50 & 50 & 7 & 10 & 5 \\
$P_{\mathrm{i}}$ (bar) & $10-25$ & $20-22$ & $2-4$ & $2-4$ & $2-4$ \\
\hline
\end{tabular}

facilitate the following analysis, some important features about these materials and corresponding testing methods for gas permeability are also extracted from literature, as listed in Table 9.

Although the compositions and mix proportion of the three concrete materials concerned herein are obviously different from other concretes collected in Figure 8, their relative permeability to either water or gas are comparable to each other. It is reported that the relative permeability to water and gas are mostly determined by shape parameter $n_{0}$ while the fitting parameter $\alpha$ has just a little influence on them [25]. Since the shape parameter $n_{0}$ indirectly evaluated for the three concretes are all near typical value 6.0 for general cement-based materials [3], the relative permeability to water and gas predicted for the three concrete materials focused herein are also similar to the experimental data measured on other cement-based materials. From this consideration, some relative permeability to water and gas reported in literature are collected and plotted in Figure 8. Importantly, it is noted that all the gas permeability plotted in Figure 8a are measured by the tri-axial permeameter with high inlet pressure about 10-25 bars. While the experimental data shown in Figure 8b are measured by the classic CEMBUREAU method with low absolute inlet pressure $P_{\mathrm{i}}$ about 2-4 bars [46], which is almost 1 order of magnitude lower than that used in the tri-axial permeameter method.

From Figure 8a, the relative gas permeability measured on the three concrete materials concerned herein obeys almost the same law with another two concrete materials CEMI and CEMV. From reference [50], the preconditioning method for unsaturated concretes CEMI and CEMV is the natural desorption and absorption methods at room temperature $20^{\circ} \mathrm{C}$, which brings rather good equilibrium effect in a long time. While the self-scaled drying-equilibrium strategy proposed herein is applied to prepare unsaturated specimens for concrete materials C19, C29 and C39. Even though this preconditioning strategy is different to the nice natural desorption and adsorption methods, the measured relative gas permeability for the three concrete materials observes almost the same law with another two concrete materials CEMI and CEMV. From this point of 


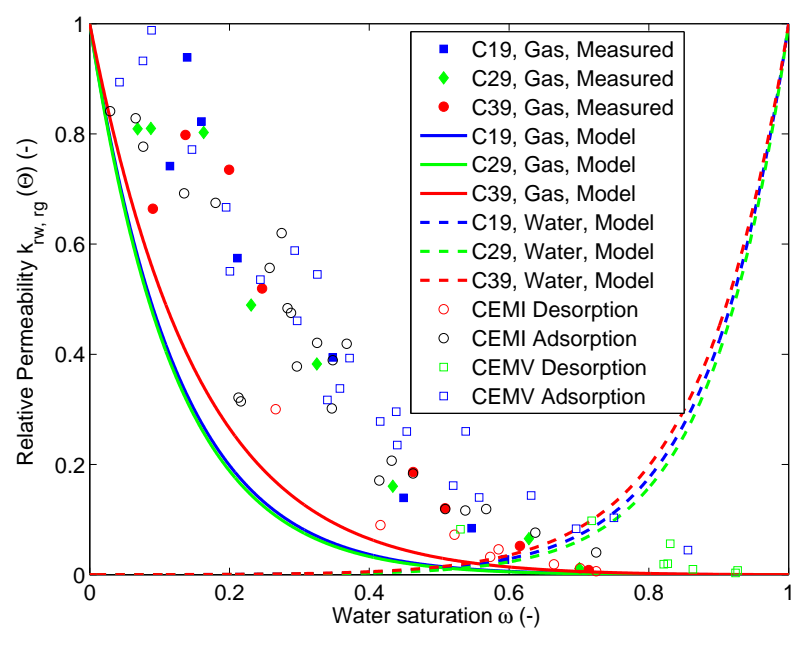

(a) Tri-axial cell

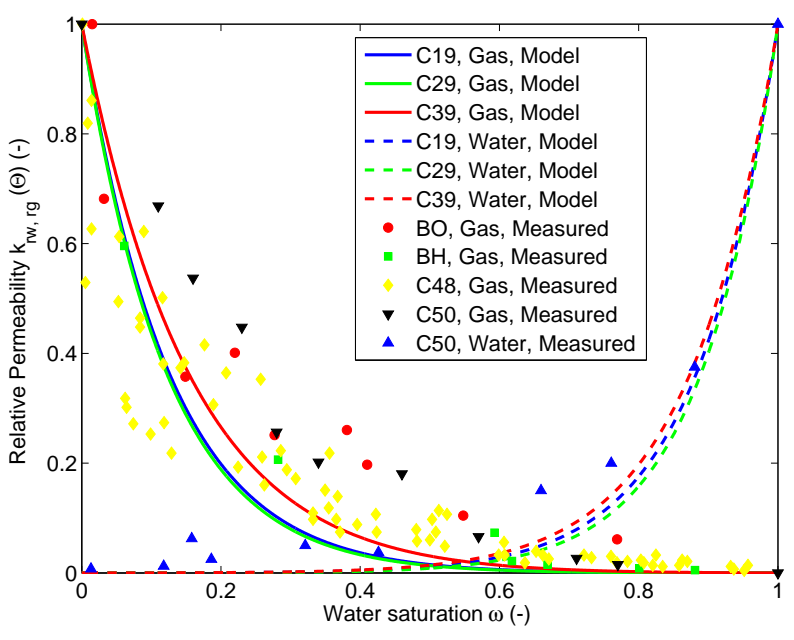

(b) Cembureau method

Figure 8: The predicted relative permeability to water and gas for various concrete materials.

view, the self-scaled preconditioning strategy brings as good effect as the natural desorption and adsorption methods to prepare unsaturated specimen with certain saturation degree. In another aspect, as discussed in Section 4.2, the surface contact with liquid water causes some influences to the microstructure of concrete materials, which makes the sorptivity measured in the second cycle scattered or even ambiguous. However, it brings little effect to the measured relative gas permeability. Therefore, the alteration of microstructure caused by contact with liquid water is rather superficial and does not obviously affect the relative gas permeability measured on thick specimen.

When comparing the predicted relative gas permeability to the experimentally measured values in Figure 8a, it can be seen that the measured relative gas permeability for C19, C29 and C39 are remarkably underestimated by the proposed model Equation (21) over the whole range of saturation degree. On the contrary, the proposed model can well capture the evolution of relative gas permeability for some other concrete materials, as displayed in Figure 8b. This unexpected difference is extremely difficult to interpret.

After thorough literature investigation, it is easy to find out that these two measurement methods are rather similar but with some important different details including the sample size, sample conditioning method, the confining pressure and the inlet gas pressure. These four factors may be responsible to the obvious difference between relative gas permeability measured by the tri-axial permeameter and CEMBUREAU methods. Firstly, it was reported that there is no size effect observable on concrete permeability if the ratio of specimen size to MSA is higher than 2.5 [68]. 
However, another experimental research suggested that specimen of small size will have higher intrinsic gas permeability [64]. Although the influence of pore structure characteristics on relative gas permeability is almost negligible [18], the size effect on relative gas permeability can be slightly observed from the experimental data reported in reference [49]. Specimen with smaller ratio of size to MSA has a litter higher relative gas permeability. Comparing the ratio of specimen size to MSA listed in Table 9, we hardly believe that the size effect is responsible to the obvious difference between relative gas permeability measured by the tri-axial permeameter and CEMBUREAU methods. Secondly, the sample preparation methodology adopted herein is as good as natural sorption method at preparing concrete specimen with uniform water content. As regards the partially saturated specimens on which the relative gas permeability shown in Figure $8 \mathrm{~b}$ are measured, they were prepared by either step-by-step sorption method ( $\mathrm{BO}$ and $\mathrm{BH}$, at $45^{\circ} \mathrm{C}$ and controlled $\mathrm{RH}$ ) or accelerated drying-equilibrium method ( $\mathrm{C} 48$ and $\mathrm{C} 50$, moderate temperature $50-80^{\circ} \mathrm{C}$ and various longer or shorter equilibrium duration). However, it seems from Figure $8 \mathrm{~b}$ that different pre-conditioning methods did not produce different relative gas permeability for various concrete materials. Therefore, different conditioning methods is also irresponsible to the concerned obvious difference between the tri-axial permeameter and CEMBUREAU methods. Thirdly, although the confining pressure in tri-axial permeameter method is remarkably higher than that in CEMBUREAU method, it is still rather small when comparing to the strength of concrete materials. Then it can be easily judged from available experimental data that the influence of confining pressure is also negligible and thus irresponsible to the obvious difference $[69,70]$. Finally, it is widely observed and accepted that the intrinsic gas permeability after the Klinkenberg effect correction is independent on the inlet gas pressure. From this rule, the inlet pressure should not be responsible to the obvious difference. Moreover, the mass for each specimen monitored before and after gas permeability testing is negligibly changed. There is no desaturation during testing and the overall water content was not altered. However, the spatial distribution of water especially the isolated liquid water islands may be affected by the much higher inlet pressure in the tri-axial permeameter method. The liquid water islands blocking the way of quick gas flow may be driven away by the action of high inlet gas pressure. As a result, the connectivity of pores available to gas flow may be promoted to increase the gas permeability and thus its relative value for unsaturated specimen. In the authors' opinion, the inlet pressure is the most remarkable difference between tri-axial permeameter and CEMBUREAU methods. Although the alteration of water spatial distribution is not supported by direct evidence, it may at least partly contribute to the observable difference between tri-axial permeameter and CEMBUREAU methods.

More importantly, the relative water permeability for concrete C50 reported in reference [49] 
can be well characterized by the proposed model equation (20), as shown in Figure 8b. Although at low saturation degree the measured relative water permeability is obviously higher than predicted value, the relative water permeability for common situation with high saturation degree agrees well with that predicted from the proposed model equation (20). It is worth noting that the reported relative water permeability for concrete C50 is also indirectly deduced from isothermal drying experiment together with water vapour sorption isotherms [8, 49]. In that method, the water retention curve is modelled by classical Van Genuchten model, which is initially and usually applied for soil materials of porous structure deviating far from cement-based materials. Whether it is suitable to cementitious materials has been questioned in another paper published by the corresponding author [25]. It is said that the capacity function derived from classic Van Genuchten model cannot satisfy the logical restriction enforced by the theoretical relationship between hydraulic diffusivity and water permeability. It makes the application of Van Genuchten model to cement-based materials doubtful and even questionable. Furthermore, the relative water permeability is directly quantified by the Mualem model with fitting parameters in Van Genuchten model and another empirical tortuosity factor varying in a great range [8, 19, 49]. In another words, the model for relative water permeability is empirically assumed or predetermined before measurement. These a priori assumptions may bring some errors to the indirectly predicted water permeability for partially saturated cement-based materials. It may be also responsible for the significant deviation about relative water permeability at low saturation degree.

\section{Concluding remarks}

- The hydraulic diffusivity and water permeability for cement-based materials are proposed to be indirectly evaluated from measured sorptivity and water vapour sorption isotherms. Assuming that the hydraulic diffusivity for cement-based materials obeys exponential law, the capillary sorptivity for initially unsaturated cement-based materials is theoretically derived. From the theoretical dependence of capillary sorptivity on initial saturation degree, the hydraulic diffusivity can be indirectly computed. Together with the water retention data translated from water vapour sorption isotherms, the unsaturated water permeability can be analytically evaluated. Moreover, the relative gas permeability can be further calculated from the relationship between relative permeability to water and gas.

- An experimental program is carefully designed and conducted to measure the water vapour sorption isotherms, capillary sorptivity, permeability to liquids and gas, as well as relative gas permeability for three concrete materials with different water to cement ratios. Based 
on the measured capillary sorptivity and water vapour sorption isotherms, the hydraulic diffusivity, unsaturated water permeability and relative gas permeability are indirectly predicted and then thoroughly compared to experimental data. It is found that the hydraulic diffusivity is not a good transport property indicating the durability potential of concrete materials. Moreover, the predicted water permeability at saturation is larger than the experimentally measured value but at the same order of magnitude. The over-estimation of water permeability is attributed to the micro-cracking induced by drying action applied in pre-conditioning process. This method can be applied to estimate the water permeability of dense concrete materials, on which the direct measurement may be not practical.

- The relative water permeability predicted herein agrees well with some reported data, which is also indirectly evaluated from isothermal drying experiments. The predicted relative gas permeability significantly underestimates the experimental data measured by the tri-axial permeameter with relatively high inlet pressure. However, it agrees well with some other reported data obtained by the classic CEMBUREAU method with lower inlet pressure. This phenomenon may be attributed to the difference of the inlet gas pressure, which needs further investigation.

- A self-scaled drying-equilibrium preconditioning strategy is proposed and applied to prepare uniformly unsaturated specimens of various saturation degrees. The analysis on measured relative gas permeability indicates that the preconditioning strategy brings as good effect as the natural sorption method in a short duration. In addition, it is also inferred from the observable scattering and deviation of sorptivity at low initial saturation degree that contact with liquid water changes the pore structure of surface layer of unsaturated cement-based material with low water content.

\section{Acknowledgment}

The financial supports from the Special National Science Foundation for Post-doctoral Scientists of China (No. 2014T70348) and the National Natural Science Foundation of China (No. 51208153 ) for the current research work are gratefully acknowledged.

\section{References}

\section{References}

[1] H. W. Reinhardt, Penetration and permeability of concrete: barriers to organic and contaminating liquids, RILEM Report 16, E\&FN Spon, London, 1997. 
[2] R. Cerny, P. Rovnanikova, Transport processes in concrete, Spon Press, London and New York, 2002.

[3] C. Hall, W. D. Hoff, Water transport in brick, stone and concrete, Spon Press, London, 2012.

[4] L. A. Richards, Capillary conduction of liquids through porous mediums, Physics 1 (5) (1931) 318-333.

[5] C. Hall, Water sorptivity of mortars and concretes: a review, Magazine of Concrete Research 41 (147) (1989) $51-61$.

[6] C. Hall, Barrier performance of concrete: a review of fluid transport theory, Materials and Structures 27 (5) (1994) 291-306.

[7] N. S. Martys, Survey of concrete transport properties and their measurement, National Institute of Standards and Technology, Gaithersburg, 1996.

[8] V. Baroghel-Bouny, M. Mainguy, O. Coussy, Isothermal drying process in weakly permeable cementitious materials - assessment of water permeability, in: International Conference on Ion and Mass Transport in CementBased Materials, 1999, pp. 59-80.

[9] F. C. de Beer, J. J. le Roux, E. P. Kearsley, Testing the durability of concrete with neutron radiography, Nuclear Instruments and Methods in Physics Research A 542 (1-3) (2005) 226-231.

[10] C. Dirksen, Determination of soil water diffusivity by sorptivity measurements, Soil Science Society of America Journal 39 (1) (1975) 22-27.

[11] D. Lockington, J. Y. Parlange, P. Dux, Sorptivity and the estimation of water penetration into unsaturated concrete, Materials and Structures 32 (5) (1999) 342-347.

[12] N. Hearn, R. H. Mills, A simple permeameter for water or gas flow, Cement and Concrete Research 21 (2) (1991) 257-261.

[13] A. S. El-Dieb, R. D. Hooton, A high pressure triaxial cell with improved measurement sensitivity for saturated water permeability of high performance concrete, Cement and Concrete Research 24 (5) (1994) 854-862.

[14] H. Loosveldt, Z. Lafhaj, F. Skoczylas, Experimental study of gas and liquid permeability of a mortar, Cement and Concrete Research 32 (9) (2002) 1357-1363.

[15] N. T. Burdine, Relative permeability calculations from pore size distribution data, Journal of Petroleum Technology 5 (3) (1953) 71-78.

[16] Y. Mualem, A new model for predicting the hydraulic conductivity of unsaturated porous media, Water Resources Research 12 (3) (1976) 513-522.

[17] M. T. Van Genuchten, A closed-form equation for predicting the hydraulic conductivity of unsaturated soils, Soil Science Society of American Journal 44 (5) (1980) 892-898.

[18] V. Baroghel-Bouny, Water vapour sorption experiments on hardened cementitious materials. Part II: Essential tool for assessment of transport properties and for durability prediction, Cement and Concrete Research 37 (3) (2007) 438-454.

[19] J. P. Monlouis-Bonnaire, J. Verdier, B. Perrin, Prediction of the relative permeability to gas flow of cement-based materials, Cement and Concrete Research 34 (5) (2004) 737-744.

[20] G. Wardeh, B. Perrin, Relative permeabilities of cement-based materials: Influence of the tortuosity function, Journal of Building Physics 30 (1) (2006) 39-57.

[21] D. G. Fredlund, A. Xing, Equations for the soil-water characteristic curve, Canadian Geotechnical Journal 31 (4) (1994) 521-532.

[22] S. L. Barbour, Nineteenth canadian geotechnical colloquim: the soil-water characteristic curve: a historical perspective, Canadian Geotechnical Journal 35 (5) (1998) 873-894. 
[23] C. Leech, D. Lockington, R. D. Hooton, G. Galloway, G. Cowin, P. Dux, Validation of mualem's conductivity model and prediction of saturated permeability from sorptivity, ACI Materials Journal 105 (1) (2008) 44-51.

[24] H. Ranaivomanana, J. Verdier, A. Sellier, X. Bourbon, Prediction of relative permeabilities and water vapor diffusion reduction factor for cement-based materials, Cement and Concrete Research 48 (1) (2013) 53-63.

[25] C. Zhou, Predicting water permeability and relative gas permeability of unsaturated cement-based material from hydraulic diffusivity, Cement and Concrete Research 58 (1) (2014) 143-151.

[26] C. Zhou, General solution of hydraulic diffusivity from sorptivity test, Cement and Concrete Research 58 (1) (2014) 152-160.

[27] C. Zhou, W. Chen, W. Wang, F. Skoczylas, Unified determination of relative permeability and diffusivity for partially saturated cement-based material, Cement and Concrete Research 67 (1) (2015) 300-309.

[28] W. W. N. Charles, M. Bruce, Advanced unsaturated soil mechanics and Engineering, Taylor \& Francis, New York, 2007.

[29] P.-G. Mohammad, C. Javier, J. K. Eileen, W. Jason, Characterizing lightweight aggregate desorption at high relative humidities using a pressure plate apparatus, Journal of Materials in Civil Engineering 24 (8) (2012) 961-969.

[30] V. Baroghel-Bouny, Water vapour sorption experiments on hardened cementitious materials Part I: Essential tool for analysis of hygral behaviour and its relation to pore structure, Cement and Concrete Research 37 (3) (2007) 414-437.

[31] N. S. Martys, C. F. Ferraris, Capillary transport in mortars and concrete, Cement and Concrete Research 27 (5) (1997) 747-760.

[32] M. Kutilek, J. Valentova, Sorptivity approximations, Transport in Porous Media 1 (1) (1986) 57-62.

[33] M. B. Parlange, S. N. Prasad, J. Y. Parlange, M. J. M. Römkens, Extension of the heaslet-alksne technique to arbitrary soil-water diffusivities, Water Resouces Research 28 (10) (1992) 2793-2797.

[34] R. R. Bruce, A. Klute, The measurement of soil-water diffusivity, Soil Science Society of America Proceedings 20 (1956) 458-462.

[35] J. Drchalová, R. Černỳ, Non-steady-state methods of determining the moisture diffusivity of porous materials, International Communications in Heat and Mass Transfer 25 (1) (1998) 109-116.

[36] C. Hall, W. D. Hoff, M. Skeldon, The sorptivity of brick: dependence on the initial water content, Journal of Physics D: Applied Physics 16 (10) (1983) 1875-1880.

[37] J. F. Young, Humidity control in the laboratory using salt solutions — a review 17 (9) (1967) 241-245.

[38] A. Xu, Water desorption isotherms of cement mortar with fly ash 8 (1) (1989) 9-23.

[39] Q. Wu, T. Rougelot, N. Burlion, X. Bourbon, Representative volume element estimation for desorption isotherm of concrete with sliced samples, Cement and Concrete Research 76 (1) (2015) 1-9.

[40] A. Wexler, S. Hasegawa, Relative humidity-temperature relationships of some saturated salt solutions in the temperature range 0 to $50^{\circ} \mathrm{C}$, Journal of Research of the National Bureau of Standards 53 (1) (1954) 19-26.

[41] S. J. Gregg, K. S. W. Sing, Adsorption, surface area, and porosity, 2nd Edition, Academic Press, London, 1982.

[42] A. W. Adamson, A. P. Gast, Physical chemistry of surfaces, Wiley, New York, 1997.

[43] R. K. Dhir, P. C. Hewlett, Y. N. Chan, Near surface characteristics of concrete: intrinsic permeability, Magazine of Concrete Research 147 (41) (1989) 87-97.

[44] F. A. L. Dullien, Porous media: fluid transport and pore structure, 2nd Edition, Academic Press, San Diego, 1992. 
[45] L. J. Klinkenberg, The permeability of porous media to liquid and gas, Drilling and Production Practice (1941) 200-213.

[46] J. J. Kollek, The determination of the permeability of concrete to oxygen by the cembureau method - a recommendation, Materials and Structures 22 (3) (1989) 225-230.

[47] RILEM TC 116-PCD, Permeability of concrete as a criterion of its durability. tests for gas permeability of concrete, Materials and Structures 32 (1) (1999) 174-179.

[48] V. Baroghel-Bouny, M. Mainguy, T. Lassabatere, O. Coussy, Characterization and identification of equilibrium and transfer moisture properties for ordinary and high-performance cementitious materials, Cement and Concrete Research 29 (8) (1999) 1225-1238.

[49] Z. A. Kameche, F. Ghomari, M. Choinska, A. Khelidj, Assessment of liquid water and gas permeabilities of partially saturated ordinary concrete, Construction and Building Materials 65 (1) (2014) 551-565.

[50] W. Chen, J. Liu, F. Brue, F. Skoczylas, C. A. Davy, X. Bourbon, J. Talandier, Water retention and gas relative permeability of two industrial concretes, Cement and Concrete Research 42 (7) (2012) 1001-1013.

[51] J. Liu, F. Agostini, F. Skoczylas, From relative gas permeability to in situ saturation measurements, Construction and Building Materials 40 (3) (2013) 882-890.

[52] Z. Zhang, M. Thiéry, V. Baroghel-Bouny, A review and statistical study of existing hysteresis models for cementitious materials, Cement and Concrete Research 57 (1) (2014) 44-60.

[53] C. Gallé, Effect of drying on cement-based materials pore structure as identified by mercury intrusion porosimetry: A comparative study between oven-, vacuum-, and freeze-drying, Cement and Concrete Research 31 (10) (2001) 1467-1477.

[54] Y. Aono, F. Matsushita, S. Shibata, Y. Hama, Nano-structural changes of c-s-h in hardened cement paste during drying at $50^{\circ} \mathrm{c}$, Journal of Advanced Concrete Technology 5 (3) (2007) 313-323.

[55] C. Hall, W. D. Hoff, S. C. Taylor, M. A. Wilson, B. Yoon, H. W. Reinhardt, M. Sosoro, P. Meredith, A. M. Donald, Water anomaly in capillary liquid absorption by cement-based materials, Journal of Materials Science Letters 14 (17) (1995) 1178-1181.

[56] H. M. Jennings, A. Kumar, G. Sant, Quantitative discrimination of the nano-pore-structure of cement paste during drying: new insights from water sorption isotherms, Cement and Concrete Research 76 (1) (2015) $27-$ 36.

[57] C. A. Leech, Water movement in unsaturated concrete: theory, experiments, models, Ph.D. thesis, School of Engineering, The University of Queensland, Brisbane (2003).

[58] E. Leong, H. Rahardjo, Review of soil-water characteristic curve equations, Journal of Geotechnical and Geoenvironmental Engineering 123 (12) (1997) 1106-1117.

[59] W. S. Sillers, D. G. Fredlund, N. Zakerzadeh, Mathematical attributes of some soil-water characteristic curve models, Geotechnical and Geological Engineering 19 (3) (2001) 243-283.

[60] J. D. Valiantzas, P. G. Kerkides, A. Poulovassilis, An improvement to the one-step outflow method for the determination of soil water diffusivities, Water Resources Research 24 (11) (1988) 1911-1920.

[61] H. Garbalinska, S. J. Kowalski, M. Staszak, Moisture diffusivity in mortars of different water-cement ratios and in narrow ranges of air humidity changes, International Journal of Heat and Mass Transfer 56 (1) (2013) $212-222$.

[62] G. S. Campbell, A simple method for determining unsaturated conductivity from moisture retention data, Soil Science 117 (6) (1974) 311-314. 
[63] D. Hillel, Fundamentals of Soil Physics, Academic Press, San Diego, California, 1980.

[64] Z. Wu, H. S. Wong, N. R. Buenfeld, Influence of drying-induced micro-cracking and related size effects on mass transport properties of concrete, Cement and Concrete Research 68 (1) (2015) 35-48.

[65] N. Hearn, C. T. Morley, Self-sealing property of concrete - experimental evidence, Materials and Structures 30 (7) (1997) 404-411.

[66] M. Zalzale, P. J. McDonald, K. L. Scrivener, A 3d lattice boltzmann effective media study: understanding the role of c-s-h and water saturation on the permeability of cement paste, Modelling and Simulation in Materials Science and Engineering 21 (8) (2013) 1-16.

[67] V. Baroghel-Bouny, M. Thiery, F. Barberon, O. Coussy, G. Villain, Assessment of transport properties of cementitious materials: a major challenge as regards durability?, Revue Européenne de Génie Civil 11 (6) (2007) 671-696.

[68] J. Verdier, M. Carcasses, J. P. Ollivier, Modelling of a gas flow measurement — application to nuclear containment vessels, Cement and Concrete Research 32 (8) (2002) 1331-1340.

[69] W. F. Brace, A note on permeability changes in geologic material due to stress, Pure and Applied Geophysics 116 (4) (1978) 627-633.

[70] M. Lion, F. Skoczylas, B. Ledesert, Determination of the main hydraulic and poro-elastic properties of a limestone from bourgogne, france, International Journal of Rock Mechanics and Mining Sciences 41 (6) (2004) 915-925. 